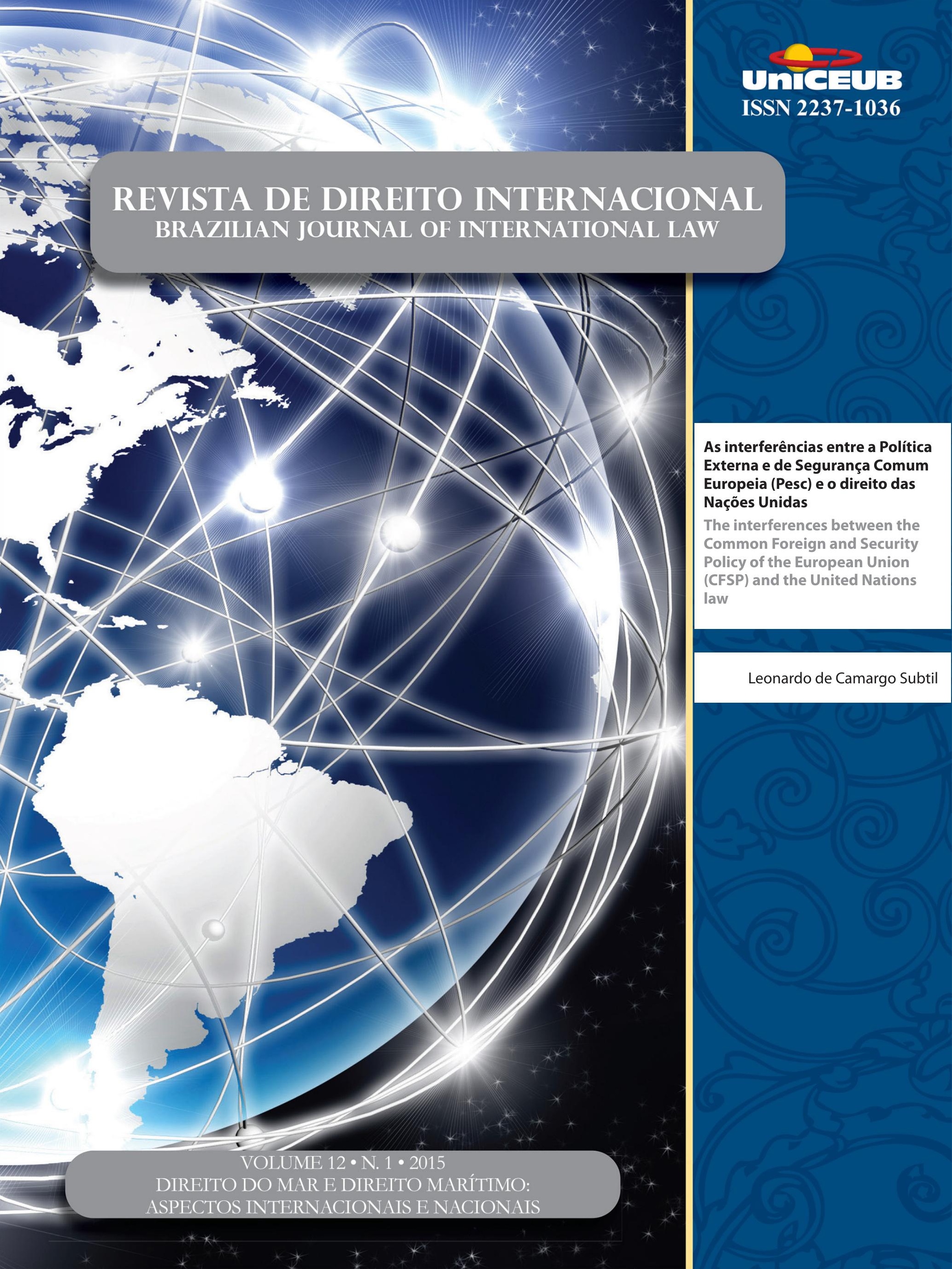




\section{Sumário}

\section{Crônicas}

CRôNICAS DA ATUALIDADE do DiREITO INTERNACIONAL ........................................................ 2

Nitish Monebhurrun (org.)

Towards a european regulation of the importation of conflict minerals?..... 2

Nitish Monebhurrun

Keeping up with the terrorists: the EU's proposed Passenger Name Records (PNR) Directive \& european security

Eshan Dauhoo

A histórica reaproximação de Cuba e EUA

Erika Braga

A contextualização da atual reivindicação da Grécia para receber indenizações por atos da Alemanha durante a Segunda Guerra Mundial . .10

Natália da Silva Gonçalves

José Eduardo Paiva Miranda de Siqueira

Crônicas da jurisprudência do Direito Internacional (CIJ/ITLOS): Decisões da Corte Internacional de Justiça e do Tribunal Internacional Sobre o Direito do Mar .14

Nitish Monebhurrun (Org.)

Corte Internacional de Justiça

Estudo da decisão da Corte Internacional de Justiça no caso Croácia v. Servia (03/02/2015) .14

Liziane Paixão Silva Oliveira e Maria Edelvacy Marinho

Questões relacionadas com a apreensão e detenção de certos documentos e dados: (Timor Leste c. Austrália) - O reconhecimento do retorno de uma relação amigável entre Timor-Leste e Austrália e a nova decisão da CIJ, 6 de maio de 2015 . 20

Gleisse Ribeiro Alves

Tribunal Internacional sobre Direito do Mar

Caso da delimitação da fronteira marítima entre o Gana e a Costa do Marfim no Oceano Atlântico: medidas cautelares $(25 / 04 / 2015)$

Nitish Monebhurrun

Comentário à Opinião Consultiva 21 do Tribunal Internacional para o Direito Do Mar [02/04/2015] (Responsabilidade do Estado de Bandeira pela pesca ilícita, não declarada ou não regulamentada) ...............25

Carina Costa de Oliveira 
CRÔNICAS DO DIREITO INTERNACIONAL DOS INVESTIMENTOS

Nitish Monebhurrun (Org.)

A inclusão da responsabilidade social das empresas nos novos Acordos de Cooperação e de Facilitação dos Investimentos do Brasil: uma revolução 33

Nitish Monebhurrun

\section{O Direito do Mar Perante as JuRisdições INTERnacionais}

CoAstal States' Rights IN THE MARITIME AREAS UNDER UNCLOS .40 Tullio Treves

TACKling illegal, unregulated And unReported Fishing: THE ITLOS Advisory OpINION on Flag State Responsibility for IUU fishing AND THE PRINCiple of DUE DiligenCE ...50 Victor Alencar Mayer Feitosa Ventura

REFLEXões PROVENIENTES do DisSENSO: UMA ANÁLISE CRÍtica A RESPEITO do CASO Austrália versus Japão Perante a Corte InTERnacional de JustiçA .......................................68 Luciana Ferna ndes Coelho

Os TRATADOS INTERNACIONAIS DE DIREITO DO MAR E SEUS EFEITOS SOBRE TERCEIROS ESTADOS ..... 86 Tiago V. Zanella

\section{InStRumentos JURÍdicos PARA A GeStÃo do MAR}

OS LIMITES DOS TERMOS BEM PÚBLICO MUNDIAL, PATRIMÔNIO COMUM DA HUMANIDADE E BENS COMUNS PARA DELIMITAR AS OBRIGAÇÕES DE PRESERVAÇÃO DOS RECURSOS MARINHOS 109 Carina Costa de Oliveira e Sandrine Maljean-Dubois

Os limites do PLANEJAMENTO DA OCUPAÇÃo SUSTENTÁVEL DA ZONA COSTEIRA BRASILEIRA ... 126 Carina Costa de Oliveira e Luciana Coelho

CORRENDO PARA O MAR NO ANTROPOCENO: A COMPLEXIDADE DA GOVERNANÇA DOS OCEANOS E A ESTRATÉGIA BRASILEIRA DE GESTÃO DOS RECURSOS MARINHOS 
A comissão de limites da Plataforma continental (CLPC) E Os DESAFios Na delineaÇÃo DAS PLATAFORMAS CONTINENTAIS ESTENDIDAS................................................... 170

Alexandre Pereira da Silva

\section{A PROTEÇÃo DO MEIO AMBIENTE MARINHO}

O gRANDE JOGo do ÁrTiCo: REFLEXões COM BASE NA PERSPECTIVA DE EXPLORAÇão ECONÔMICA

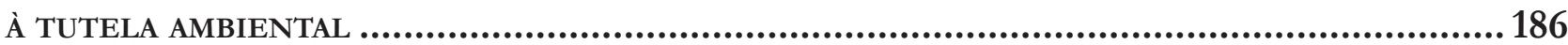

Fernando Rei e Valeria Cristina Farias

Instrumentos Públicos e Privados para a reparação do dano ambiental causado por DERRAMAMENTO DE ÓLEO NO MAR SEM ORIGEM DEFINIDA: AS MANCHAS ÓRFÃS

Renata Brockelt Giacomitti e Katya R. Isaguirre-Torres

O DIREITO INTERNACIONAL PRIVADO E A RESPONSABILIDADE CIVIL EXTRACONTRATUAL POR DANOS AMBIENTAIS CAUSADOS POR TRANSPORTES MARÍTIMOS À LUZ DO DIREITO BRASILEIRO ....... 217 Inez Lopes

A NECESSIDADE DE REPENSAR OS MECANISMOS DE RESPONSABILIDADE AMBIENTAL EM CASO DE riscos de VAZamento de PETRóleo Na Zona Econômica Exclusiva do BrasiL

Marcelo D. Varella

\section{Problemáticas do Direito Marítimo}

A FisCALIZAÇão SANitÁRIA DAS EMBARCAÇÕES EM ÁGUAS JURISDICIONAIS BRASILEIRAS: NOTAS aCERCA da (IN)efetividade da Súmula 50 da AGU

Joedson de Souza Delgado e Ana Paula Henriques da Silva

A IMO E A REPRESSÃo AO ROUBO ARMADO CONTRA NAVIOS: DA RETÓRICA INTERNACIONAL À COOPERAÇÃO REGIONAL

André Panno Beirão e Charles Pacheco Piñon

\section{O Direito do Mar diante da Pirataria}

O DIREITO INTERNACIONAL EM FACE DA PIRATARIA EM ALTO-MAR: UMA PERSPECTIVA CRÍTICA.289 Maiquel Ângelo Dezordi Wermuth e Rafaela Correa 
Pirataria marítima: A EXPERIÊnCIA Somália

Eduardo Augusto S. da C. Schneider

\section{Temas Gerais}

DRAWING THE LINE: ADDRESSING ALLEGATIONS OF UNCLEAN HANDS IN INVESTMENT ARBITRATION*

Mariano de Alba

Para Que Serve a história do Direito internacional?

George Rodrigo Bandeira Galindo

As interferências entre a Política Externa e de Segurança Comum Europeia (Pesc) e O DiREITO DAS NaÇões UNIDAS

Leonardo de Camargo Subtil

Introdução Às regras de aplicaÇão da Convenção da ONU Sobre Contratos de ComPRA E VENDA INTERNACIONAL DE MERCADORIAS E O DIREITO INTERNACIONAL PRIVADO BRASI-

LEIRO 380

Paul Hugo Weberbauer e Eugênia Cristina Nilsen Ribeiro Barza

A REgulaÇÃo das EMPRESAS TRANSNACIONAIS ENTRE AS ORDENS JURÍDICAS ESTATAIS E NÃO ESTATAIS.

Mateus de Oliveira Fornasier e Luciano Vaz Ferreira

OUtLAWING HATE SPEECH IN DEMOCRATIC STATES: THE CASE AGAINST THE INHERENT LimitAtions doctrine concerning Article 10 (1) of the European Convention on Human

Rights 416

Stefan Kirchner 


\title{
As interferências entre a Política Externa e de Segurança Comum Europeia (Pesc) e o direito das Nações Unidas*
}

\author{
The interferences between the Common \\ Foreign and Security Policy of the European \\ Union (CFSP) and the United Nations law
}

Leonardo de Camargo Subtil**

\section{Resumo}

O presente trabalho tem por objetivo apresentar uma análise sobre as interrelações entre a Política Externa e de Segurança Comum Europeia (PESC) e o Direito das Nações Unidas na sociedade internacional. Para tanto, utilizou-se do método teórico-pragmático para a observação das categorias escolhidas, tendo, como técnica de pesquisa, a exploração bibliográfica, com consulta dogmática, doutrinária e jurisprudencial em relação aos temas explorados na pesquisa. Nas conclusões obtidas, verificou-se que artigo 103 da Carta das Nações Unidas não se caracteriza como uma regra de hierarquia jurídica ou como uma regra de conflito de normas. Pelo contrário, trata-se de uma regra de conflito de obrigações em Direito Internacional. Por fim, somente se deve decidir pela primazia das obrigações decorrentes do Direito das Nações Unidas em relação àquelas do Direito da União no caso de evidente conflito de obrigações, como na problemática trazida pelo presente artigo.

Palavras-chave: Direito da união. Direito das Nações Unidas. Política externa e de segurança comum europeia. Teoria do direito.

\section{Abstract}

This article aims to present an analysis on the interrelations between the Common Foreign and Security Policy of the European Union (CFSP) and the United Nations Law in international society. For this purpose, we have made an option for a theoretical and pragmatic method to observe the selected legal categories. As a technique of research, we have chosen a bibliographic exploration, with dogmatic, doctrinal and jurisprudential consultation, on issues related to this paper. In conclusion, it was found that Article 103 of the United Nations Charter should not be seen as a hierarchical legal rule or as a rule of conflict of laws. On the contrary, it is a rule of conflict of obligations in International Law. Finally, it should only be decided in favor of the primacy of the obligations under the United Nations Law in relation to those of the European Union Law in case of obvious conflict of obligations, such as the issue raised by this paper. 
Keywords: European Union law. United Nations law. Common foreign and security policy of the European Union. Theory of law.

\section{INTRODUÇÃO}

C'est ce qui fonde l'oscillation interminable de l'argumentation juridique libérale internationaliste entre les deux pôles de l'utopie et de l'apologie. ${ }^{1}$

Em 1989, Martti Koskenniemi publica a obra From apology to utopia: the structure of international legal argument, desvelando os momentos de oscilação argumentativa do Direito Internacional Público, da apologia de um mundo descritivo à utopia de uma ordem desejada pela sociedade internacional. Toda essa estrutura normativa em oscilação, transposta também na teoria do Direito enquanto apologia ou utopia, permeará não somente a construção e o desenvolvimento das categorias científicas, mas o debate em torno das relações entre a ordem jurídica da União Europeia e a internacional, em especial, a quaestio juris do Direito como técnica de poder ou do Direito enquanto fim em si.

Dentro desse contexto, será desenvolvido o presente estudo Interferências entre Política Externa e de Segurança Comum Europeia (PESC) e o Direito das Nações Unidas, no sentido de desvelar caracteres comuns e conflitantes na interação entre o Direito Internacional Público e o Direito da União ${ }^{2}$. Em particular, nessa concepção interativa e, ao mesmo tempo paradoxal, como será observado, a preocupação essencial é justamente de não perder a ideia de sistema, seja do sistema jurídico, seja do sistema político-institucional, bem como a ideia de sistema social, a fim de não desnaturar a ideia de sistema normativo como quadro epistemológico de estabilidade, de integridade e de coerência normativas.

Esses paradoxos constitutivos do sistema jurídico-internacional - que o fazem evoluir cientificamente

1 KOSKENNIEMI, Martti. From apology to utopia: the structure of the international legal argument. Cambridge: Cambridge University Press, 2005. p. 58.

2 No presente artigo, utiliza-se a expressão Direito da União - e não Direito Comunitário - para indicar o novo Direito da União Europeia ante as modificações trazidas pelo Tratado de Lisboa, de 01 de dezembro de 2009, que emendou o Tratado da União Europeia (TUE - Maastricht, 1992) e o Tratado constitutivo da Comunidade Europeia (TCE, Roma, 1957), este renomeado para Tratado sobre o Funcionamento da União Europeia (TFUE).
- podem ser observados em diversos subsistemas jurídicos como, por exemplo, o Direito da União e o Direito Internacional Público. Esta observação de cunho geral e introdutório concerne às questões normativas o campo de criação ou de análise dogmática das regras jurídicas —, institucionais - o campo de aplicação e de interpretação normativas - e reflexivas sobre essas últimas dimensões no plano crítico para assegurar a integridade normativa e, ao mesmo tempo, a transformação evolutiva inscrita na sobrevivência do próprio sistema jurídico internacional.

Para tanto, nessa análise de interação entre o Direito Internacional Público e o Direito da União, será utilizada a metodologia teórico-pragmática, no sentido da construção teórica a partir dos fenômenos normativos e sociais - do plano da cotidianidade (everydayness $)^{3}-\mathrm{e}$ da análise destes a partir da reflexividade do Direito em suas próprias categorias científicas. Além disso, a técnica de pesquisa a ser utilizada será a de exploração bibliográfica, com consulta dogmática, doutrinária e jurisprudencial em relação aos temas explorados na pesquisa, em livros, sítios e periódicos científicos.

A estrutura do presente artigo, ao ser definida, seguiu os seguintes objetivos: 1) delimitar, normativamente e institucionalmente, a Política Externa e de Segurança Comum (PESC) na União Europeia, desde o Tratado de Roma (1957) até as modificações trazidas pelo Tratado de Lisboa (2009); 2) demonstrar a paradoxal relação entre as obrigações decorrentes da Política Externa e de Segurança Comum Europeia (PESC) e do Direito das Nações Unidas ${ }^{4}$, em especial, da análise do artigo 103 da Carta das Nações Unidas.

Convém salientar que a estruturação do estudo fora realizada com base no seguinte problema de pesquisa: quando houver conflito entre as prescrições ${ }^{5}$ de Política Externa e de Segurança Comum Europeia (PESC) decorrentes do Direito da União - e de Paz e Segurança internacionais - em virtude das Resoluções expedidas pelo Conselho de Segurança com base no capítulo

3 RICHARDSON, John. Existencial epistemology: a heideggerian critique of the cartesian project. New York: Oxford University Press, 1986. p. 15.

4 Por Direito das Nações Unidas, entenda-se, em especial, a moldura normativo-institucional do sistema internacional pós-criação da Organização das Nações Unidas, em 26 de junho de 1945.

5 Prescrições normativas, com cunho obrigacional, em virtude de decisões tomadas politicamente, criadoras de obrigações jurídicas, com sustentação no Direito da União ou no Direito das Nações Unidas. 
VII da Carta das Nações Unidas, haveria uma relação de primazia no que tange as obrigações assumidas pela União Europeia em virtude do Direito da União e do Direito das Nações Unidas?

Sendo assim, a União Europeia imersa no conflito e na divergência acima descritos, numa concepção unitária e integrativa do Direito, deveria seguir a regra da primazia das obrigações decorrentes do Direito da União ou pender para a primaz̨ia das obrigacõoes decorrentes do Direito das Nações Unidas? Essas são, ainda que resumidamente, as linhas fundamentais do estudo a ser desenvolvido a seguir, com base nas premissas e objetivos traçados.

\section{A tRANSFormação NORMATIVO- INSTITUCIONAL DA POLÍTICA EXTERNA E DE SEGURANÇA COMUM NA UNIÃo EUROPEIA}

L'Europe a avancé pas à pas, de traités en traités. Le chemin est jalonné d'accords partiels, de crises, vite surmontées. Le trait le plus frappant est que l'Europe a pu paraitre bloquée, à certaines époques, mais qu'elle n'a jamais reculé. ${ }^{6}$

Valéry Giscard d'Estaing, Presidente da Convenção Europeia, ex-Presidente francês (1974-1981), em seu discurso introdutório à Convenção sobre o futuro da Europa, refere o processo de desenvolvimento de uma Europa dos tratados. Os marcos normativos da construção europeia, desde seu surgimento histórico com a Comunidade Europeia do Carvão e do Aço (CECA $)^{7}$, em 18 de abril de 1951, com o Tratado de Paris, seguiram duas faces de uma mesma moeda, a ambição (apologia) e a ficção (utopia).

A ambição europeia incide sobre o parcialmente construído, os acordos transitórios, as concertações políticas fragmentadas, as crises duradouras, as reuniões interestatais permanentes, e todas essas etapas fizeram os marcos normativos de criação e de desenvolvimento europeus tocar a realidade europeia, isto é, desenvolver-se com base em uma faticidade europeia, essencialmente regional ${ }^{8}$. Assim, tem-se o modelo da apologia europeia,

6 ESTAING, Valéry Giscard. Discours introductif à la Convention sur l'avenir de l'Europe. Disponível em: <http://www.senat.fr/europe/ convention_2002/discours_vge_28022002.pdf>. Acesso em: 03 fev. 2014.

7 Os seus inspiradores foram Robert Schuman, Ministro francês dos Negócios Estrangeiros, e Jean Monnet, o seu primeiro Presidente. Além disso, os seus países fundadores foram: França, Itália, Alemanha Ocidental, Bélgica, Países Baixos e Luxemburgo.

8 A expressão "fato regional" foi desenvolvida de maneira baseado na realidade construída politicamente e normativamente pari passu, com considerada perseverança ${ }^{9}$, tendo em vista que "as modificações políticas e jurídicas espraiam-se por quase cinquenta anos, sem que esmoreça a vontade de fazer coisas, mesmo se o ritmo não seja o mesmo a todos os momentos." 10

$\mathrm{Na}$ esteira do forte pragmatismo político, ligado, portanto, à ideia da ambição europeia, líderes como Jean Monnet, Robert Schuman, Paul-Henri Spaak, Alcide de Gasperi e Konrad Adenauer consagram a ideia da integração calçada no fundamento das transferências parciais e graduais de soberania formal dos Estados. Essas transferências asseguram o fundamento de sua competência e de seu poder, ligados ao que efetivamente se dá por construído no espaço europeu - a dimensão real de poder (apologia), pois justamente "[...] ocurre siempre que la divergencia entre los elementos de hecho y la regla jurídica aumenta hasta originar una tensión excesiva; entonces, el derecho se halla expuesto a perder contacto con la vida." 11

Na outra face, reside a ficção europeia, incidindo sobre o porvir europeu, a necessidade de construção de uma Europa estável — outrora marcada por instabilidade política e debilidade institucional das duas grandes guerras mundiais - e, ao mesmo tempo, transformadora de sua própria realidade política, pois “[...] esses objetivos e essas ações buscam instaurar a paz política, interna e externa, e o bem-estar social mediante o desenvolvimento econômico. Essa proposta adquire contornos nítidos após 1945, mas já apresenta sinais nítidos de persistência desde finais do século XVIII.’12

analítica por Laurence Boisson de Chazournes. Ver: BOISSON DE CHAZOURNES, Laurence. Les relations entre organisations régionales et organisations universelles. In: L'ACADÉMIE DE DROIT INTERNATIONAL DE LA HAYE. Recueil des cours de l'Académie du droit international de la Haye. Leiden: M. Nijhoff, 2011. t. 347. p. 79-406. p. 105-106.

9 Para Estevão de Rezende Martins, na construção da União Europeia, desde a Conferência de Messina, em junho de 1955, até a Convenção Europeia, de fevereiro de 2002, 05 (cinco) são os princípios que a sustentaram: a) persistência; b) perseverança; c) paciência; d) prudência; e) parceria. MARTINS, Estevão de Rezende. Parcerias almejadas: política externa, segurança, defesa e história na Europa. Belo Horizonte: Fino Traço, 2012. p. 12.

10 MARTINS, Estevão de Rezende. Parcerias almejadas: política externa, segurança, defesa e história na Europa. Belo Horizonte: Fino Traço, 2012. p. 16.

11 VISSCHER, Charles de. Teorias y realidades en derecho internacional público. Barcelona: Bosch, 1962. p. 12.

12 MARTINS, Estevão de Rezende. Parcerias almejadas: política externa, segurança, defesa e história na Europa. Belo Horizonte: Fino Traço, 2012. p. 13. 
Nesse mesmo sentido, em 9 de maio de 1950, Robert Schuman, Ministro dos Assuntos Estrangeiros da França, profere a Declaração Schuman em que propõe a criação da Comunidade Europeia do Carvão e do Aço (CECA). Em seu pronunciamento faz-se claramente perceptível a dimensão ficcional europeia, eis que "la paix mondiale ne saurait être sauvegardée sans des efforts créateurs à la mesure des dangers qui la menacent." ${ }^{\text {13 }}$

Entre essas duas faces da ambição e da ficção europeias, entre apologia e utopia, começa a surgir um novo modelo, o do corpus europeu, e a sobrevivência das novas concertações políticas e do corpo normativo europeu passa dos Estados - individualmente considerados - para justamente uma nova realidade orgânica sui generis, a União Europeia. ${ }^{14}$ É justamente nessa preocupação relativa ao corpus institucional europeu - que surge a necessidade histórica e institucional de criação e de desenvolvimento de mecanismos de preservação política em matéria de política externa e segurança comum do espaço europeu. Pensar a preservação política do espaço europeu passa sobremaneira pela criação e pela preservação do próprio Direito como instrumento, antes de tudo, de manutenção do status quo (sustentação política).

Gradualmente, tais mecanismos de defesa e segurança acompanham a evolução do espaço europeu, tratado a tratado, como sublinhara Valéry Giscard d'Estaing, ${ }^{15}$ conformando a transformação normativo-institucional da Política Externa e de Segurança Comum na União Europeia.

\subsection{Do Tratado de Roma (1957) ao Tratado de Maastricht (1992)}

Entre a ausência política e a Política Externa e de Segurança Comum (PESC)

13 SCHUMAN, Robert. La déclaration Schuman du 9 mai 1950. Disponível em: <http://europa.eu/about-eu/basic-information/symbols/europe-day/schuman-declaration/index_fr.htm>. Acesso em: 03 fev. 2014

14 Neste estudo, quando se citar União Europeia, obviamente, considerar-se-á toda evolução histórica e, posteriormente, institucional, até se chegar ao nível mais elevado de integração políticoeconômica, a União Europeia. Nesse desenvolvimento, a importância da Comunidade Europeia do Carvão e do Aço (CECA), da Comunidade Econômica de Defesa (CED), da Comunidade Econômica da Energia Atômica (CAEA), da Comunidade Econômica Europeia e da União Europeia.

15 ESTAING, Valéry Giscard. Discours introductif à la convention sur l'avenir de l'Europe. Disponível em: <http://www.senat.fr/europe/ convention_2002/discours_vge_28022002.pdf>. Acesso em: 03 fev. 2014.
Embora seja possível falar em processo de integração europeia somente no século XX, no sentido que se apreende atualmente, já se pode observar a vontade de construção de um espaço europeu como entidade política ${ }^{16}$ na reorganização desse espaço por ocasião do Congresso de Viena, em 1814-1815. No século seguinte, após a I Guerra Mundial, um apoio renovado por uma Europa unificada ganha força no movimento Pan-Europeu, fundado pelo austríaco Richard Coudenhove-Kalergi, além da proposta do francês Aristide Briand por uma união federal europeia. ${ }^{17}$

Com o início da II Guerra Mundial, a ideia de construção de uma Europa integrada permanece como possível recurso para frear a Alemanha nazista, reconstituindo a racionalidade pacífica do espaço europeu, da lógica desarmamentista e da solução pacífica dos litígios, como, por exemplo, o Projeto Europeu da Paz (1946) proposto por Winston Churchill, por um Conselho da Europa no âmbito de um sistema federal. ${ }^{18}$

No desenvolvimento do espaço de integração europeu, em seu início eminentemente econômico, em especial, na segunda metade do século XX, no período pós II Guerra Mundial, o desafio inicial consistia em sua reconstrução econômica, social e política. Além disso, as razões da integração europeia em seu estágio preliminar, isto é, o impulso primeiro para a integração, deram-se em razão da necessidade de maior aproximação, reconciliação e coesão do continente europeu. ${ }^{19}$ Por fim, as rupturas políticas no espaço europeu, em decorrência de guerras e conflitos regionais ou internacionais, contribuíram sobremaneira às instabilidades econômicas que assolaram o continente europeu, em especial, desde o século XIX.

A construção da integração europeia, na medida do fortalecimento dos vínculos políticos — para além do aspecto inicial meramente econômico - estimula, por conseguinte, o desenvolvimento de mecanismos de ges-

16 Nesse sentido de construção de um espaço comum europeu, Saint-Simon (1760-1825) fora inspirado pelo Congresso de Viena (1814-1815) a imaginar uma comunidade europeia com um parlamento supranacional.

17 MARTINS, Estevão de Rezende. Parcerias almejadas: política externa, segurança, defesa e história na Europa. Belo Horizonte: Fino Traço, 2012. p. 14.

18 MARTINS, Estevão de Rezende. Parcerias almejadas: política externa, segurança, defesa e história na Europa. Belo Horizonte: Fino Traço, 2012. p. 14.

19 PETITEVILLE, Franck. La politique internationale de l'union européenne. Paris: Les Presses de Sciences Po, 2006. 
tão da sobrevivência e da falibilidade da própria integração europeia, da segunda metade do século XX ao início do século XXI.

Assim, a partir de decisões políticas - inicialmente somente entre alguns Estados - , vai-se construindo uma pauta comum no espaço europeu em torno da chamada política externa e de segurança comum. Essas decisões, dentro da ideia de estabilização do espaço europeu, do aumento dos vínculos políticos entre os Estados e da necessidade de elaboração de um processo de tomada de decisões progressivamente vinculantes, acabam adquirindo normatividade por meio dos tratados constitutivos do atual Direito da União. A questão central, portanto, dessa primeira parte do estudo, diz respeito à evolução normativa do tratamento da política externa e da segurança comum na União Europeia.

A primeira proposta europeia data de 1950, o chamado Plano Pleven - em homenagem ao Primeiro-Ministro e Presidente do Conselho francês René Pleven - , projeto concebido e escrito por Jean Monet. Como objetivo, tal Plano almejava a criação de um exército europeu comum, tendo sido objeto de negociações entre os Estados-membros da Comunidade Europeia do Carvão e do Aço (CECA), de 1950 a 1952, conduzindo à aprovação do Tratado que instituiu a Comunidade Europeia de Defesa (CED).$^{20}$ Entretanto, o Plano Pleven fracassou após ter sido rejeitado pela Assembleia Nacional francesa, em 30 de agosto de 1954 (319 votos contra 254).

Com os Tratados de Roma de 1957, que instituíram a Comunidade Europeia, ainda não havia referência a uma cooperação política exterior, mas somente uma concertação econômica entre França, Itália, Alemanha Ocidental, Bélgica, Países Baixos e Luxemburgo. Convém observar que os Tratados de Roma instituíram, primeiramente, a Comunidade Econômica Europeia (CEE) - almejando a criação de um mercado comum generalizado, e a Comunidade Europeia da Energia Atômica (Euratom) - com o propósito de criar uma Comunidade da Energia Atômica -, entrando em vigor em 1 de janeiro de 1958. Nesse sentido, com a de-

20 A Comunidade Europeia de Defesa (CED) era um projeto político, apresentado em 1953, que visava à criação de uma estrutura federal ou confederativa com o propósito de coordenação das Forças Armadas de toda Europa. UNIÃO EUROPEIA. Sinteses da legislação da União Europeia: Tratado de Amsterdam. Disponível em: <http:/ / europa.eu/legislation_summaries/institutional_affairs/treaties/amsterdam_treaty/a19000_pt.htm>. Acesso em: 31 jan. 2014 bilidade política ainda saliente numa esfera meramente interestatal, não havia dispositivo normativo ou programático tratando da política externa ou de qualquer espécie de segurança comum no espaço europeu.

Em 1961, com o Plano Fouchet, proposto pelo Presidente francês Charles de Gaulle, mas escrito pelo Embaixador francês Christian Fouchet, a ideia era de construir uma União de Estados, uma alternativa às Comunidades Europeias. Além disso, o próprio artigo $2^{\circ}$ do Plano Fouchet destacava que "L'Union a pour but de rapprocher, de coordonner et d'unifier la politique des États membres dans les domaines d'intérêt commun: politique étrangère, économie, culture et défense." ${ }^{21}$. Apesar da introdução da agenda de política estrangeira e de defesa numa projeção futura, (03) três objeções conduziram ao fracasso das negociações: a) a incerteza quanto à participação da Grã-Bretanha; b) as divergências sobre a questão de uma defesa europeia que aspire à independência em relação à Aliança Atlântica; c) o caráter excessivamente intergovernamental das instituições propostas, que levava ao risco de esvaziar de conteúdo o carácter supranacional das instituições comunitárias existentes. ${ }^{22}$

Dez anos após o fracasso do Plano Fouchet, surge o chamado Relatório Davignon ${ }^{23}$, em 27 de outubro de 1970, apresentado no Encontro de Luxemburgo, estabelecendo os primeiros passos rumo à cooperação política na Europa. Constitui, assim, um avanço inicial em matéria de cooperação política entre os Estados. Por exemplo, na esteira de fortalecimento da integração política da União, foi estabelecido um sistema de consultas regulares sobre os pontos essenciais da política externa da União entre os Ministros de Relações Exteriores dos Estados membros, como dispõe a Segunda Parte do Relatório: "Les ministres proposent ce qui suit: Soucieux de réaliser des progrès dans le domaine de l'unification politique, les gouvernements décident de coopérer en matière de politique étrangère." ${ }^{24}$

21 UNIÃO EUROPEIA. Sínteses da legislação da União Europeia: Tratado de Amsterdam. Disponível em: < http://europa.eu/legislation_summaries/institutional_affairs/treaties/amsterdam_treaty/ a19000_pt.htm>. Acesso em: 31 jan. 2014.

22 UNIÃO EUROPEIA. Sinteses da legislação da União Europeia: Tratado de Amsterdam. Disponível em: < http://europa.eu/legislation_summaries/institutional_affairs/treaties/amsterdam_treaty/ a19000_pt.htm>. Acesso em: 31 jan. 2014.

23 O Relatório Davignon foi escrito pelo Diplomata belga Étienne Davignon, também denominado Relatório de Luxemburgo. 24 CENTRE VIRTUEL DE LA CONNAISANCE DE L'EUROPE. Rapport Davignon: rapport des ministres des affaires 
Assim, no Relatório Davignon, tem-se o surgimento da chamada Cooperação Política Europeia, ainda num estágio embrionário e de proposição de ideais, ainda distante dos mecanismos de implementação, com as seguintes premissas: a) assegurar, por uma informação e consultas regulares, uma melhor compreensão mútua sobre os grandes problemas da política internacional; b) reforçar sua solidariedade, favorecendo a harmonização dos pontos de vista, a concertação das atitudes e, quando parecer possível e desejável, as ações comuns.

Em 23 de julho de 1973, foi editado o Segundo Relatório sobre Cooperação Política Europeia em matéria de Política Estrangeira, o Relatório Copenhague, com a fixação das modalidades dessa cooperação intergovernamental europeia. Convém salientar que os objetivos desse segundo Relatório são os mesmos do Relatório Davignon, com foco na compreensão mútua dos grandes temas de política internacional e no reforço do sistema de consultas mútuas.

No sentido de aprofundar, consolidar e expandir a política externa europeia, o Relatório Copenhague reconhece os progressos dos 03 (três) anos da edição do Relatório Davignon: "Les ministres constatent que les mécanismes mis en place par le rapport de Luxembourg caractérisés par leur pragmatisme ont fait la preuve de leur souplesse et de leur efficacité." 25 Além disso, reforça a necessidade da Europa marcar seu lugar nos assuntos internacionais enquanto entidade distinta a exercer influência determinante no equilíbrio internacional e sobre o futuro da então Comunidade Econômica Europeia (CEE). Por fim, consolida sua vocação de abertura, de progresso, de paz e de cooperação, respeitando as alianças de seus Estados membros e as relações de boa vizinhança, bem como do conjunto dos países em desenvolvimento. ${ }^{26}$

Com a Cimeira de Paris, em 9 de dezembro de 1974, organizada pelo então Presidente francês Valéry Gis-

étrangères des Etats membres sur les problèmes de l'unification politique. Disponível em: <http://www.cvce.eu/obj/rapport_davignon_luxembourg_27_octobre_1970-fr-4176efc3-c734-41e5-bb90d34c4d17bbb5.html>. Acesso em: 01 fev. 2014.

25 CENTRE VIRTUEL DE LA CONNAISANCE DE L'EUROPE. Rapport Copenhague: Deuxième rapport sur la coopération politique européenne en matière de politique étrangère. Disponível em: <http://www.cvce.eu/obj/deuxieme_rapport_ sur_la_cooperation_politique_europeenne_en_matiere_de_politique_etrangere_copenhague_23_juillet_1973-fr-8b935ae1-0a3842d4-a97e-088c63d54b6f.html>. Acesso em: 02 fev. 2014.

26 TERPAN, Fabien. La politique étrangère, de sécurité et de défense de l'union européenne. Paris: La Documentation Française, 2010. card d'Estaing, cria-se o chamado Conselho Europeu. Sua origem dá-se em torno dos problemas internos, mas também dos enfrentados pela Comunidade Econômica Europeia (CEE) no exterior, como demonstra o item 4 do Comunicado:

4. Les chefs de gouvernement réaffirment, dans la perspective de l'unification européenne, leur volonté d'arrêter progressivement des positions communes et de mettre en œuvre une diplomatie concertée dans tous les domaines de la politique internationale qui affectent les intérêts de la Communauté européenne. La présidence exerce la fonction de porte-parole des Neuf et se fait leur interprète sur le plan diplomatique. Elle veille à ce que la concertation nécessaire ait toujours lieu en temps utile. ${ }^{27}$

Nela, portanto, os Chefes de Estados e de Governo da Comunidade Econômica Europeia (CEE) decidem realizar 03 (três) reuniões ao ano, harmonizando posição nos seguintes pontos a serem desenvolvidos: a) eleições diretas para o Parlamento Europeu; b) criação da União Econômica e Monetária; c) elaboração do Relatório Tindmans, ${ }^{28}$ sobre as Comunidades Europeias até o final de 1975.

A partir da Cimeira de Paris, em 1974, começa a observar-se a evolução de percepção em relação à política externa da então Comunidade Econômica Europeia (CEE), com a necessidade da construção, muito além da agenda política de integração, dos mecanismos de implementação e de desenvolvimento da ação externa europeia.

Em 13 de outubro de 1981, no chamado Relatório de Londres, os Ministros de Relações Exteriores dos 10 (dez) Estados membros da Comunidade Europeia avaliaram a evolução da Cooperação Política Europeia (CPE), reconhecendo a importância, em especial, dos Relatórios de Luxemburgo (1970) e de Copenhague (1973). Além disso, a necessidade da tomada da posição comum dos 10 (dez) Estados em relação à política externa da Comunidade Europeia, conforme o preâmbulo do Relatório: "Les ministres des affaires étrangères notent que les Dix sont de plus en plus à même de pouvoir

27 CENTRE VIRTUEL DE LA CONNAISANCE DE L'EUROPE. Sommet de Paris: Communiqué final de la réunion des chefs de gouvernement de la Communauté (Paris, 9 et 10 décembre 1974). Disponível em: <http://www.cvce.eu/obj/communique_final_du_ sommet_de_paris_9_et_10_decembre_1974-fr-2acd8532-b271-49edbf63-bd8131180d6b.html>. Acesso em: 02 fev. 2014.

28 Leo Tindemans, Primeiro-Ministro belga à época. 
parler d'une seule voix sur le plan international."’29. Por fim, o Relatório mantém a separação estrita entre as Comunidades Europeias e a Cooperação Política Europeia $(\mathrm{CPE}){ }^{30}$

Com o Ato Único Europeu (AUE),${ }^{31}$ houve o reconhecimento da necessidade de certa coordenação das políticas estrangeiras e a formalização de procedimentos que ingressassem como regras de Direito Primário. Assim, fez-se presente a formalização jurídica da Cooperação Política Europeia (CPE), com o estabelecimento de Secretariado próprio em Londres. ${ }^{32}$

O principal objetivo do processo de construção europeia era a realização do mercado interno, o que seria dificilmente exequível com base nos tratados existentes na ordem jurídica europeia, tendo em vista que o processo de decisão no Conselho Europeu requeria unanimidade para se proceder à harmonização da legislação. ${ }^{33}$ Em razão disso, a Conferência Intergovernamental que conduziu ao Ato Único Europeu tinha duplo mandato. Por um lado, com a finalidade de compor um tratado em matéria de política externa e segurança comum e, de outro lado, um Ato que emendasse o Tratado que havia instituído a Comunidade Econômica Europeia (CEE), nas seguintes matérias: a) processo de tomada de decisão no Conselho; b) competências da Comissão; c) poderes do Parlamento Europeu; d) alargamento das competências das Comunidades.

No título III do Ato Único Europeu (AUE), foram estatuídas as disposições relativas à Cooperação Europeia em Matéria Política (CPE), no próprio artigo 30.

29 CENTRE VIRTUEL DE LA CONNAISANCE DE L'EUROPE. Rapport Londres: rapport sur la coopération politique européenne (Londres, 13 octobre 1981). Disponível em: <http:// www.cvce.eu/obj/rapport_sur_la_cooperation_politique_europeenne_londres_13_octobre_1981-fr-869a63a6-4c28-4e42-8c41-efd2415cd7dc.html>. Acesso em: 02 fev. 2014.

30 MARTINS, Estevão de Rezende. Parcerias almejadas: política externa, segurança, defesa e história na Europa. Belo Horizonte: Fino Traço, 2012. p. 49.

31 Assinado em Luxemburgo, em 17 de Fevereiro de 1986, por (09) nove Estados-Membros e, em 28 de Fevereiro de 1986, pela Dinamarca, Itália e Grécia, constitui a primeira alteração de grande porte do Tratado que institui a Comunidade Econômica Europeia (CEE). Entrou em vigor em 1 de Julho de 1987.

32 MARTINS, Estevão de Rezende. Parcerias almejadas: política externa, segurança, defesa e história na Europa. Belo Horizonte: Fino Traço, 2012. p. 49.

33 UNIÃO EUROPEIA. Sinteses da legislação da União Europeia: Ato Único Europeu (AUE). Disponível em: < http://europa.eu/ legislation_summaries/institutional_affairs/treaties/treaties_singleact_pt.htm>. Acesso em: 1 fev. 2014.
Dentre as premissas mais significativas a cargo das Altas Partes Contratantes ${ }^{34}$ — inseridas no esforço de aplicação comum de uma política estrangeira europeia (artigo 30, 1) —, estavam:

a) a manutenção do sistema mútuo de consultas em matéria de política externa com vistas à convergência das posições estatais e a realização de ações comuns (artigo 30, II, a);

b) a precaução em evitar qualquer ação ou tomada de posição prejudiciais à eficácia da Cooperação Europeia em matéria de Política Estrangeira (CPE), nas relações internacionais ou no seio das organizações internacionais (artigo 30, II, d);

c) associação estreita do Parlamento Europeu à Cooperação Política Europeia (CPE), com troca mútua e permanente de informações (artigo 30, IV);

d) construção progressiva sobre as questões de segurança, com vistas ao desenvolvimento de uma identidade europeia em matéria de política externa (artigo 30, VI, a).

e) equiparação em matéria de privilégios e imunidades entre os membros do Secretariado da Cooperação Política Europeia (CPE) aos membros das missões diplomáticas das Altas Partes contratantes situadas no local do estabelecimento do Secretariado.

Com essas transformações consubstanciais no tratamento da política externa e de segurança europeia, sobretudo a alínea $d$ acerca da construção de uma identidade europeia, em 7 de fevereiro de 1992 é assinado o Tratado sobre a União Europeia (TUE) ou Tratado de Maastricht,$^{35}$ que cria a União Europeia, sustentada em 03 (três) pilares: as Comunidades Europeias, a Política Externa e de Segurança Comum (PESC) e a cooperação

34 As Altas Partes Contratantes eramas seguintes: Bélgica, Alemanha, Dinamarca, Grécia, Espanha, França, Irlanda, Itália, Luxemburgo, Holanda, Portugal, Reino Unido.

35 O Tratado de Maastricht entra em vigor somente em 1 de novembro de 1993. Ao Preâmbulo, seguem-se 07 (sete) Títulos. O Título I prevê disposições comuns às Comunidades, à Política Externa Comum e à Cooperação Judiciária. O Título II inclui as disposições que alteram o Tratado CEE e os Títulos III e IV alteram, respectivamente, os Tratados CECA e CEEA. O Título V introduz as disposições relativas à Política Externa e de Segurança Comum (PESC) e o Título VI contém as disposições relativas à cooperação nos domínios da justiça e dos assuntos internos (JAI). As disposições finais constam do Título VII. UNIÃO EUROPEIA. Tratado sobre a União Europeia. Tratado de Maastricht. Disponível: <http://eur-lex. europa.eu/fr/treaties/dat/11992M/htm/11992M.html>. Acesso em: 1 fev. $2014 .$. 
policial e judiciária em matéria penal, como demonstra o quadro abaixo:

\begin{tabular}{|c|c|c|}
\hline \multicolumn{3}{|c|}{ União Europeia - Campos com relação com política externa } \\
\hline Comunidades Europeias & $\begin{array}{c}\text { Política externa e de segurança } \\
\text { comum (Pesc) }\end{array}$ & Cooperação policial e judiciária em matéria penal \\
\hline $\begin{array}{l}\text { - Política de comércio exterior } \\
\text { - Cooperação para o desenvol- } \\
\text { vimento (Cotonou) } \\
\text { - Ajuda humanitária }\end{array}$ & $\begin{array}{l}\text { - Política externa em sentido } \\
\text { estrito } \\
\text { - Política de defesa } \\
\text { - Política de segurança }\end{array}$ & $\begin{array}{l}\text { - Controle das fronteiras externas } \\
\text { - Combate ao terrorismo, ao tráfico de dro- } \\
\text { gas e às demais formas de criminalidade in- } \\
\text { ternacional }\end{array}$ \\
\hline
\end{tabular}

A Política Externa e de Segurança Comum (PESC), prevista no Título V do Tratado de Maastricht, substitui a Cooperação Política Europeia (CPE), do Ato Único Europeu (AUE), instituindo uma nova sistemática europeia de tratamento da matéria.

Esse segundo pilar institui um processo de decisão interestatal que recorre, em grande parte, à tomada de decisão por unanimidade, com os seguintes objetivos principais do Tratado sobre a União Europeia (TUE): a) salvaguardar os valores comuns, os interesses fundamentais e a independência da União; b) reforçar a segurança da União Europeia e de seus Estados membros de todas as maneiras; c) manter a paz e o reforço da segurança internacional, conforme os princípios da Carta das Nações Unidas, bem como dos princípios da Ata final de Helsinki e da Carta de Paris; d) promover a cooperação internacional; e) desenvolver a democracia e o Estado de Direito, bem como o respeito aos Direitos Humanos e as liberdades fundamentais. ${ }^{37}$

Com vistas à consagração desses objetivos principais, (02) dois são os mecanismos estabelecidos no Tratado de Maastrich: a) a instauração de uma cooperação sistemática entre os Estados membros; b) a execução gradual de ações comuns nos domínios onde os Estados membros tenham interesses comuns importantes. ${ }^{38}$ Além disso, os Estados membros devem apoiar, ativamente e sem reservas, a política externa e de segurança

36 MARTINS, Estevão de Rezende. Parcerias almejadas: política externa, segurança, defesa e história na Europa. Belo Horizonte: Fino Traço, 2012. p. 41. Adaptado pelo Autor.

37 UNIÃO EUROPEIA. Tratado sobre a União Europeia. Tratado de Maastricht. Disponível: <http://eur-lex.europa.eu/fr/treaties/ dat/11992M/htm/11992M.html>. Acesso em: 1 fev. 2014.

38 UNIÃO EUROPEIA. Tratado sobre a União Europeia. Tratado de Maastricht. Disponível: <http://eur-lex.europa.eu/fr/treaties/ dat/11992M/htm/11992M.html>. Acesso em: 1 fev. 2014. da União Europeia em um espírito de lealdade e de solidariedade mútuas, abstendo-se de toda ação contrária aos interesses da União Europeia ou suscetível de prejudicar sua eficácia como força coerente nas relações internacionais, conforme dispõe o artigo J.3, do Tratado sobre a União Europeia (TUE). ${ }^{39}$

Outra introdução importante diz respeito ao procedimento para adotar ações comuns em política estrangeira e de segurança. A competência para a tomada de decisão é do Conselho, sob a base de orientações gerais do Conselho Europeu. Conforme dispõe o Tratado de Maastricht ${ }^{40}$, quando o Conselho chega a uma ação comum, deve fixar os seus objetivos gerais e particulares que motivam a União, bem como os meios, procedimentos, condições e, se necessário, a duração aplicável a sua execução. Por fim, quando da adoção e do transcorrer de uma ação comum, o Conselho define as questões em nome das quais as decisões devem ser tomadas em maioria qualificada. Nessas decisões que exigirem maioria qualificada, introduzida pela sistemática de Maastricht, os Estados membros devem evitar impedir, sempre que possível, que tenha unanimidade quando uma maioria qualificada seja favorável à decisão.

A União Europeia integra, com o Tratado sobre a União Europeia (TUE), a ideia de política estrangeira à noção de segurança em uma política da União e dos Estados membros, com o reconhecimento do Conselho Europeu. ${ }^{41}$ Além disso, estabelece a definição dos obje-

39 UNIÃO EUROPEIA. Tratado sobre a União Europeia. Tratado de Maastricht. Disponível: <http://eur-lex.europa.eu/fr/treaties/ dat/11992M/htm/11992M.html>. Acesso em: 1 fev. 2014.

40 UNIÃO EUROPEIA. Tratado sobre a União Europeia. Tratado de Maastricht. Disponível: <http://eur-lex.europa.eu/fr/treaties/ dat/11992M/htm/11992M.html>. Acesso em: 1 fev. 2014.

41 MARTINS, Estevão de Rezende. Parcerias almejadas: política externa, segurança, defesa e história na Europa. Belo Horizonte: Fino Traço, 2012. p. 51. 
tivos e dos mecanismos comuns de execução no corpo do próprio Tratado de Maastricht. ${ }^{42}$

\subsection{Da Estratégia Comum Europeia (ECE) à institucionalização normativa da Estratégia Europeia de Segurança (EES) pelo Tratado de Lisboa (2009)}

A Conferência interestatal que se realizou durante do Conselho Europeu de Amsterdam, em junho de 1997, reformou a Política Externa e de Segurança Comum (PESC) de modo conservador. Entretanto, os mecanismos colocados à disposição dos Estados lhes permitem avançar no caminho de uma Política Externa e de Segurança Comum (PESC) consideravelmente mais eficaz e coerente. ${ }^{43}$

Essa leitura surge do Tratado de Amsterdam, assinado em 2 de outubro de 1997, que entrou em vigor em 1 de maio de 1999. Em relação à Política Externa e de Segurança Comum (PESC), o Tratado de Amsterdam passa a adotar uma Estratégia Comum Europeia (ECE), focando nos seguintes caracteres:

1. Para além da instituição de um mecanismo de abstenção construtiva, o novo processo de decisão dá maior espaço à chamada maioria qualificada, adotando a mencionada Estratégia Comum Europeia (ECE) no seio da Política Externa e de Segurança Comum (PESC). Assim, se a Estratégia Comum Europeia for adotada por unanimidade pelo Conselho Europeu, as decisões tomadas sob essa base (incluso as ações comuns e as posições comuns) necessitam apenas maioria qualificada. Além disso, as estratégias comuns devem contribuir para reforçar a coerência da ação externa da União, isto é, todas as decisões que executam uma ação comum ou uma posição comum serão adotadas por maioria qualificada. ${ }^{44}$

Questão interessante ocorre quando um membro do Conselho declarar que, por importantes e expressas razões de política nacional, tenciona opor-se à concessão de uma autorização por maioria qualificada, quando, en-

42 UNIÃO EUROPEIA. Tratado sobre a União Europeia. Tratado de Maastricht. Disponível: <http://eur-lex.europa.eu/fr/treaties/ dat/11992M/htm/11992M.html>. Acesso em: 1 fev. 2014.

43 IORDAN, Cristian. La définition progressive d'une politique européenne de sécurité. Romanian Journal Of European Affairs, Bucharest, v. 13, n. 2, p. 67-79, 2013. p. 76.

44 TERPAN, Fabien. La politique étrangère, de sécurité et de défense de l'union européenne. Paris: La Documentation Française, 2010. tão, não se procederá à votação, conforme redação dada pelo Tratado de Amsterdam ao artigo 23 do Tratado da União Europeia (ex-artigo J.13)..$^{45}$ Além disso, o Conselho, deliberando por maioria qualificada, pode solicitar que a questão seja submetida ao Conselho Europeu, a fim de ser tomada uma decisão por unanimidade. ${ }^{46}$ Excetuam-se, nos dois casos anteriores, as decisões a serem tomadas no domínio militar ou da defesa.

2. O Tratado de Amsterdam tenta remediar os limites da Política Externa e de Segurança Comum (PESC), criando a função de Alto-Representante para a PESC, dando redação ao artigo 26 do Tratado da União Europeia (ex-artigo J.16), embora desprovida de capacidades de coerção para exercer uma verdadeira influência internacional. Sua função, inicialmente, “[...] é de assessorar a presidência rotativa da União nas relações com Estados terceiros. Forma, com o ministro das Relações exteriores do país no exercício da presidência e com o comissário de Assuntos Exteriores, a assim chamada "troika" das relações exteriores." ${ }^{\prime 7}$

A figura do Alto-Representante, confiada ao Secretário-Geral do Conselho, beneficia-se do apoio de um mecanismo de análise e de previsão comum: a unidade de planificação da política e de alerta rápido, chamado de unidade política, permitindo o reforço da coerência e da integridade da ação externa da União. Em especial, a unidade política propõe, sob a autoridade do Alto-Representante, opções à presidência do Conselho, "Afin de donner à l'Union européenne "un visage et une voix" (ou, pour reprendre l'expression ironique d'Henry Kissinger, "un numéro de téléphone")." ${ }^{48}$

3. O Conselho Europeu recebe maior competência de orientação, em especial, em matéria de segurança e de defesa. Nesse campo, ocorre uma aproximação entre a União Europeia e a União da Europa Ocidental (UEO), tendo em vista que "[...] para incrementar de imediato a operacionalidade da União na gestão de cri-

45 UNIÃO EUROPEIA. Tratado sobre a União Europeia. Tratado de Maastricht. Disponível: <http://eur-lex.europa.eu/fr/treaties/ dat/11992M/htm/11992M.html>. Acesso em: 1 fev. 2014.

46 UNIÃO EUROPEIA. Tratado sobre a União Europeia. Tratado de Maastricht. Disponível: <http://eur-lex.europa.eu/fr/treaties/ dat/11992M/htm/11992M.html>. Acesso em: 1 fev. 2014..

47 MARTINS, Estevão de Rezende. Parcerias almejadas: política externa, segurança, defesa e história na Europa. Belo Horizonte: Fino Traço, 2012. p. 58

48 FRANCE. Ministère des Affaires Étrangères). Guide de la PESC. Disponível em: <http://www.rpfrance.eu/IMG/guide_pesc.pdf>. Acesso em: 2 fev. 2014. 
ses, o Tratado de Amsterdã adotou, na Pesc, a "agenda de Petesberg”, da União da Europa Ocidental. A UEO, a prática é absorvida por Amsterdã." 49

Convém salientar que o próprio Tratado de Amsterdam dá redação ao artigo 17 do Tratado da União Europeia (ex-artigo J.7), no sentido de integração da própria União da Europa Ocidental (UEO) à União, se o Conselho Europeu assim o desejar. Essa integração dá-se de tamanha forma no Tratado de Amsterdam que a própria "agenda de Petesberg" fora retirada do modelo da União da Europa Ocidental (UEO), contendo as seguintes missões: a) missões humanitárias; b) missões de salvamento; c) missões de manutenção da paz; d) missões de força para gestão de crises e instauração da paz.

Um instrumento inovador adotado pelo próprio Tratado de Amsterdam, na Declaração relativa à União da Europa Ocidental, ${ }^{50}$ adotada anteriormente pelo Conselho de Ministros da União da Europa Ocidental, em 22 de junho de 1997, é justamente a cooperação em matéria armamentista no contexto de racionalização do mercado europeu de armamentos e de criação de uma Agência Europeia do Armamento (AEA).

Outrossim, a designação dos Representantes Especiais $^{51}$ da União Europeia, conforme redação dada pelo Tratado de Amsterdam ao artigo 18 do Tratado da União Europeia (TUE) (ex-artigo J.8), foi tida como uma das evoluções no sentido de se construir uma identidade exterior europeia, institucionalizada pelo Tratado de Amsterdam. Entre outras razões, a designação dos Representantes Especiais ${ }^{52}$ permite uma melhor visibilidade da União Europeia, além de facilitar o diálogo político e o desenvolvimento da integração regional..$^{53}$

49 MARTINS, Estevão de Rezende. Parcerias almejadas: política externa, segurança, defesa e história na Europa. Belo Horizonte: Fino Traço, 2012. p. 58.

50 UNIÃO EUROPEIA. Tratado de Amsterdam. Disponível em: <http://eur-lex.europa.eu/fr/treaties/dat/11997D/htm/11997D. html>. Acesso em: 1 fev. 2014.

51 Na prática da União Euopeia, tal designação começa, pré-normativamente, em 1996, para a região dos Grandes Lagos (África) e para o acompanhamento do processo de paz no Oriente Médio.

52 Na qualidade de Representantes Especiais da União Europeia, Aldo Ajello (Italiano) para os Grandes Lagos Africanos (1996), Francesc Vendrell (Espanhol) para o Afeganistão (2002), Marc Otte (Bélgica) para o processo de paz no Oriente Médio (2003), Adriaan Jacobovits de Szeged (Holandês) para a Moldávia (2005), Jan Kubis (Eslováquia) para a Ásia Central (2005), Pekka Haavisto (Finlandês) para o Sudão (2005), Erwan Fouéré (Irlandês) para a ex-Ioguslávia (2005), Christian Schwarz-Schilling (Alemanha) para a Bosnia-Herzegovina (2006), Peter Semnby (Sueco) para o Sul do Cáucaso (2006). 53 PETITEVILLE, Franck. La politique internationale de l'union euro-
Nomeados pelo Conselho, por maioria qualificada, após a abertura das candidaturas aos Estados membros da União Europeia, os candidatos viajam durante o período de candidatura onde se submetem a entrevistas com o Secretário-geral do Conselho e o Alto-Representante para a Política Externa e de Segurança Comum (PESC). Após esses trâmites, o Alto-Representante recomenda uma das candidaturas ao Comitê Político e de Segurança (COPS) ${ }^{54}$ cuja criação começa a tomar corpo no Encontro de Helsinki (1999), na Decisão 2000/143/PESC, e no Encontro de Nice (2001), responsável pela aprovação ou não da candidatura proposta. ${ }^{55}$ Como suas funções, além de dar à União Europeia uma dimensão política concreta pelo mundo, tem-se a representação da União nas regiões e países instáveis para sua promoção política, bem como a facilitação do diálogo político nas regiões em conflito. ${ }^{56}$

O Tratado de Amsterdam, portanto, configura a Política Externa e de Segurança Comum (PESC) da União Europeia em novos objetivos, ${ }^{57}$ demonstrando o fortalecimento da integração europeia nesta matéria, conforme redação dada ao artigo 11 do Tratado da União Europeia (TUE) (ex-artigo J.1,7), quais sejam: a) a salvaguarda dos valores comuns, dos interesses fundamentais, da independência e da integridade da União, de acordo com os princípios da Carta das Nações Unidas; b) o reforço da segurança da União, sob todas as formas; c) a manutenção da paz e o reforço da segurança internacional, de acordo com os princípios da Carta das Nações Unidas, com os princípios da Ata Final de Helsinki e com os objetivos da Carta de Paris, incluindo os concernentes às fronteiras externas.

A Estratégia Comum Europeia (ECE), portanto, surge como instrumento jurídico da Política Externa e de Segurança Comum (PESC), com redação dada pelo

péenne. Paris: Les Presses de Sciences Po, 2006.

54 Instituído de forma permanente pela Decisão do Conselho 2001/78/PESC, de 22 de janeiro de 2001, o Comitê Político e de Segurança (COPS) acompanha a situação internacional no campo da Política Estrangeira e de Segurança Comum (PESC) e da Política de Segurança e de Defesa Comum (PSDC). Responde pela definição e pelo acompanhamento da resposta da União Europeia a uma situação de crise.

55 FRANCE. Ministère des Affaires Étrangères). Guide de la PESC. Disponível em: <http://www.rpfrance.eu/IMG/guide_pesc.pdf>. Acesso em: 2 fev. 2014.

56 PETITEVILLE, Franck. La politique internationale de l'union européenne. Paris: Les Presses de Sciences Po, 2006.

57 Dentre outras mudanças significativas traziadas pelo Tratado de Amsterdam em matéria de Política Externa e de Segurança Comum (PESC) estão: a) Atenuação do pricípio da unanimidade; b) Utilização mais frequente do recurso ao princípio da maioria qualificada. 
Tratado de Amsterdam ao artigo 13 do Tratado sobre a União Europeia (TUE) (ex-artigo J.3), prevendo justamente que o Conselho Europeu decidirá sobre as estratégias comuns que serão executadas pela União no campo em que os Estados membros tenham interesses comuns importantes ${ }^{58}$. Essa Estratégia Comum Europeia (ECE) delimita seus objetivos, sua duração e seus meios para fornecer à União Europeia, sendo um importante mecanismo no seio da Política Externa e de Segurança Comum (PESC).

Em sequência ao Tratado de Amsterdam (1997), na Cimeira ou Conselho Europeu de Colônia, de 1999, houve o fortalecimento da Política Externa Comum de Segurança e de Defesa (PESD), bem como a divulgação, pelo Conselho Europeu, de uma declaração visando ao fortalecimento da Política Externa e de Segurança Comum (PESC) na União Europeia. ${ }^{59}$ Logo em seguida, em 2000, formalizou-se o Tratado de Nice, com a institucionalização do Comitê de Política e Segurança (COPS) e da Política Externa Comum de Segurança e de Defesa (PESD) ${ }^{60}$ Além disso, "dotou a PESC de regras melhoradas do processo de decisão - expansão da aplicação da maioria qualificada — e da necessária infraestrutura organizacional." ${ }^{61}$

Em 2001, com a Cimeira ou Conselho Europeu de Laeken, reunidos os Chefes de Estado no seio do Conselho da União Europeia, elaborou-se a Declaração de Laeken sobre o futuro da Europa, a ser posteriormente presidida por Valéry Giscard d'Estaing e que prepararia o Tratado para uma Constituição da Europa (TECE). ${ }^{62}$ Em termos operacionais, o Conselho de Laeken decla-

58 UNIÃO EUROPEIA. Tratado de Amsterdam. Disponível em: <http://eur-lex.europa.eu/fr/treaties/dat/11997D/htm/11997D. html>. Acesso em: 1 fev. 2014.

59 MARTINS, Estevão de Rezende. Parcerias almejadas: política externa, segurança, defesa e história na Europa. Belo Horizonte: Fino Traço, 2012. p. 58.

60 A Política Externa Comum de Segurança e de Defesa (PESD) tem por objetivo fortalecer a operacionalidade externa da União pela capacitação civil e militar a prevenir conflitos e a superar crises. VIGNES, Daniel. L'Union européenne, acteur civil et militaire dans la gestion des crises internationales: la PESD, politique européenne de sécurité et de défense. In: YEE, Sienho; MORIN, Jacques-Yvan. Multiculturalism and international law: essays in honour of Edward McWhinney. Leiden: Martinus Nijhoff, 2009. p. 393-414.

61 MARTINS, Estevão de Rezende. Parcerias almejadas: política externa, segurança, defesa e história na Europa. Belo Horizonte: Fino Traço, 2012. p. 59.

62 MARTINS, Estevão de Rezende. Parcerias almejadas: política externa, segurança, defesa e história na Europa. Belo Horizonte: Fino Traço, 2012. p. 59. ra, simbolicamente, a prontidão da Tropa de Choque da União dentro da estrutura da Política Externa e de Segurança Comum (PESC).

Entretanto, é com a assinatura do Tratado de Lisboa, em 13 de dezembro de 2007, que se configura uma Estratégia Europeia de Segurança (EES), inserida na Política Externa e de Segurança Comum (PESC) (KING, 2005). Convém salientar, por rigor analítico, que o Tratado de Lisboa reformou o funcionamento da União Europeia, em 1 de dezembro de 2009, quando entrou em vigor, emendando o Tratado sobre a União Europeia (TUE) e o Tratado que estabelece a Comunidade Europeia (TCE), que veio a ser denominado Tratado sobre o Funcionamento da União Europeia - TFUE. ${ }^{63}$

Além do aumento do processo de tomada de decisões por meio de maioria qualificada no Conselho da União Europeia, do incremento do Parlamento Europeu, da eliminação dos 03 (três) pilares, da criação de um Presidente do Conselho Europeu com mandato mais longo e de um Alto Representante da União para os Negócios Estrangeiros e a Política de Segurança, o Tratado de Lisboa vinculou o Tratado sobre a União Europeia (TUE) à Carta dos Direitos Fundamentais da União Europeia. ${ }^{64}$

No artigo 21 do Tratado sobre a União Europeia (TUE), reformado pelo Tratado de Lisboa, reorganizou-se os objetivos relativos à Ação Externa da União (AEU) rumo a um significativo grau de cooperação em todos os domínios das relações internacionais, dentre os quais se situam:

a) salvaguardar os seus valores, interesses fundamentais, segurança, independência e integridade;

b) consolidar e apoiar a democracia, o Estado de direito, os Direitos do Homem e os princípios do Direito Internacional;

63 O Tratado sobre o Funcionamento da União Europeia (TFUE) segue, em virtude do seu artigo 205, o Tratado sobre a União Europeia (TUE), que será abordado na sequência deste artigo. Especificamente, em relação à Ação Externa da União, trata das seguintes temáticas: 1) Disposições gerais; 2) Política Comercial Comum; 3) Cooperação com países terceiros e ajuda humanitária; 4) Medidas restritivas; 5) Acordos internacionais; 6) Relações da União com as Organizações Internacionais e países terceiros e Delegações da União; 7) Cláusula de solidariedade. UNIÃO EUROPEIA. Tratado sobre o Funcionamento da União Europeia. Disponível em: <http://eurlex.europa.eu/LexUriServ/LexUriServ.do?uri=OJ:C:2010:083:004 7:0200:pt:PDF>. Acesso em: 3 fev. 2014.

64 UNIÃO EUROPEIA. Carta dos Direitos Fundamentais da União Europeia. Disponível em: <http://www.europarl.europa.eu/charter/pdf/text_pt.pdf>. Acesso em: 3 fev. 2014. 
c) preservar a paz, prevenir conflitos e reforçar a segurança internacional, em conformidade com os objetivos e os princípios da Carta das Nações Unidas, com os princípios da Ata Final de Helsinki e com os objetivos da Carta de Paris, incluindo os respeitantes às fronteiras externas;

d) apoiar o desenvolvimento sustentável nos planos econômicos, social e ambiental dos países em desenvolvimento, tendo como principal objetivo erradicar a pobreza;

e) incentivar a integração de todos os países na economia mundial, inclusivamente por meio da eliminação progressiva dos obstáculos ao comércio internacional;

f) contribuir para o desenvolvimento de medidas internacionais para preservar e melhorar a qualidade do ambiente e a gestão sustentável dos recursos naturais em escala mundial, a fim de assegurar um desenvolvimento sustentável;

g) prestar assistência a populações, países e regiões confrontados com catástrofes naturais ou de origem humana;

h) promover um sistema internacional baseado numa cooperação multilateral reforçada e uma boa governança ao nível mundial.

Tais conteúdos programáticos previstos nos objetivos da Ação Externa da União (AEU), com vistas as suas efetivações, devem ser tomados a partir do que anteriormente eram chamadas de estratégias, ações e posições comuns, agora, substituídas pelas chamadas Decisões, conforme o artigo 31 do Tratado sobre a União Europeia (TUE): "As decisões ao abrigo do presente capítulo são tomadas pelo Conselho Europeu e pelo Conselho, deliberando por unanimidade, salvo disposição em contrário do presente capítulo. Fica excluída a adopção de actos legislativos". ${ }^{65}$

A regra da unanimidade, contudo, pode ser atenuada pela maioria qualificada do Conselho (artigo 31, 2), desde que este decida, por unanimidade, em torno da opção por deliberar sobre o mérito da matéria segundo o critério da maioria qualificada (artigo 31, 3). Essa possibilidade de flexibilização do quórum não se aplica às decisões sobre matéria militar e de defesa, quando

65 UNIÃO EUROPEIA. Tratado sobre a União Europeia. Tratado de Maastricht. Disponível: <http://eur-lex.europa.eu/fr/treaties/ dat/11992M/htm/11992M.html>. Acesso em: 1 fev. 2014 somente será aceito o critério da unanimidade.

Questão importante a ser observada reside na impossibilidade da edição de atos legislativos em matéria de Política Externa e de Segurança Comum (PESC), em virtude do referido dispositivo, ficando sob competência exclusiva do Conselho Europeu ${ }^{66}$ e pelo Conselho da União Europeia. ${ }^{67}$

Observando-se toda a transformação normativo-institucional da União Europeia, na esteira das modificações trazidas pela reforma do Tratado de Lisboa (2007), verifica-se a mutação do cargo de Alto-Representante para a Política Externa e de Segurança Comum (PESC) para a figura do Alto-Representante da União para Alto-Representante da União para os Negócios Estrangeiros e a Política de Segurança ${ }^{68}$ Esse Alto-Representante deve ser nomeado pelo Conselho Europeu, por maioria qualificada, com a aprovação do Presidente da Comissão, conforme o artigo 18 do Tratado da União Europeia. ${ }^{69}$

Além disso, possui as seguintes atribuições principais: a) preside o Conselho dos Negócios Estrangeiros (artigo 18); b) executa a Política Estrangeira (artigo 23); c) direito de proposição para a política estrangeira (artigo 27); d) representação em face de Estados terceiros e Organizações Internacionais (artigo 27); e) dirige o Serviço Europeu para a Ação Externa (SEAE); f) busca uma solução quando um membro do Conselho declarar que, por razões vitais e expressas de política nacional, tenciona opor-se à adoção de uma decisão a tomar por maioria qualificada (artigo 31.2); g) coordenação das atividades dos Estados membros no seio das Organizações Internacionais para tornar visível o interesse da União Europeia (artigo 34); h) consulta e informação regular do Parlamento Europeu sobre a evolução da Política Externa e de Segurança Comum (PESC) (artigo 36).

66 Instituição da União Europeia, no âmbito da qual os chefes de Estado e de Governo dos países membros se reúnem cerca de 04 (quatro) vezes por ano para debater as prioridades políticas da União Europeia.

67 É no âmbito do Conselho da União Europeia que os Ministros de cada Estado-Membro se reúnem para adotar legislação e assegurar a coordenação das políticas da União Europeia. MARTINS, Estevão de Rezende. Parcerias almejadas: política externa, segurança, defesa e história na Europa. Belo Horizonte: Fino Traço, 2012. p. 68. 68 Desde agosto de 2014, o cargo é exercido por Federica Mogherini (Itália).

69 MARTINS, Estevão de Rezende. Parcerias almejadas: política externa, segurança, defesa e história na Europa. Belo Horizonte: Fino Traço, 2012. p. 69. 
Outro organismo criado pelas modificações trazidas pelo Tratado de Lisboa foi o Serviço Europeu de Ação Exterior (SEAE), conforme o artigo 27, 3, do Tratado sobre a União Europeia (TUE). Com a função de colaborar com a diplomacia dos Estados membros, composta por funcionários do Secretariado-Geral do Conselho e da Comissão e pelo pessoal dos serviços diplomáticos nacionais, tendo sua organização e funcionamento definidos pelo Conselho. Tal importância deve-se ao fato de que não havia representação diplomática tradicional na União Europeia, pois esta se dava somente por meio das representações dos seus Estados membros nos países terceiros. ${ }^{70}$

A organização do Serviço Europeu de Ação Exterior (SEAE), em síntese, possui as seguintes características, dentro da Estratégia Europeia de Segurança (EES): a) administração central e delegações nos Estados terceiros, bem como nas Organizações Internacionais; b) sob a autoridade do Alto-Representante da União para os Negócios Estrangeiros e a Política de Segurança, auxilia os presidentes do Conselho Europeu e da Comissão Europeia; c) cooperar com o Secretário-Geral do Conselho, com os serviços da Comissão (consultas recíprocas) e com os serviços diplomáticos dos Estados membros; d) um orçamento próprio, mas responsabilidade da Comissão por certos instrumentos (estabilidade, cooperação com países industrializados, relações públicas e missões de observação eleitoral).

Por fim, uma das peculiaridades atinentes à Estratégia Europeia de Segurança (EES), inserida na Política Externa e de Segurança Comum (PESC), diz respeito à incompetência do Tribunal de Justiça da União Europeia para as matérias contidas no Capítulo 1, Título $\mathrm{V}$, à exceção da forma dos procedimentos executados e das atribuições institucionais para exercício de competências, conforme o artigo 24, 1, do Tratado sobre a União Europeia.

Essa blindagem em relação ao controle da ação externa e das políticas de segurança e de defesa europeias, desenhadas na Política Externa e de Segurança Comum (PESC) e concretizadas pela Estratégia Europeia de Segurança (EES), guarda uma relação intrínseca de autoproteção em relação ao ambiente externo e, ao mesmo tempo, paradoxal em relação às interferências com o

70 MARTINS, Estevão de Rezende. Parcerias almejadas: política externa, segurança, defesa e história na Europa. Belo Horizonte: Fino Traço, 2012. p. 65-66. chamado Direito das Nações Unidas. Eis a problemática a ser desenvolvida a seguir.

\section{A relação paradoxal entre a política EXTERNA E DE SEGURANÇA COMUM EUROPEIA E $O$ DiREITO das Nações UNIDAs}

Étudier la place des Communautés dans l'ordre internationale [...] à soulever une série de problèmes et à faire état de situations que l'on n'a pas coutume d'évoquer à propos d'une organisation internationale. ${ }^{71}$

Estudar o lugar da União Europeia no seio da comunidade internacional, atualizando a frase de Jean Groux e Philippe Manin ${ }^{72}$, possibilita levantar uma série de problemas, de contrariedades, de incompatibilidades e de situações desconhecidas no espaço europeu. Essas irritações, causadas a partir do desenvolvimento institucional da União Europeia, conduz a 03 (três) compreensões autônomas e interdependentes dos fenômenos, ao mesmo tempo, gerando crises e evoluções no sistema europeu: a) dimensão política; b) dimensão Jurídica; e c) dimensão epistemológica.

Ao partir de uma construção institucional complexa como a da União Europeia, o risco de redução da complexidade a uma espécie de banalização é considerável, tendo em vista que independentemente de quais sejam as controvérsias em torno da construção da entidade jurídica europeia e de seus modos de inserção na vida internacional "[...] reste une constante, sorte d'irreductible de l'analyse du phénomène européen: l'Union Européenne n'est toujours pas sur le chemin de la " banalisation »." "73 $\mathrm{O}$ risco de maior banalização do fenômeno europeu dá-se na mesma proporção da desconsideração das 03 (três) dimensões mencionadas como estruturas autônomas e interdependentes.

Enquanto a dimensão política possui suas estruturas e códigos próprios (autonomia) de estruturação no seio social, como, por exemplo, os discursos diplomáticos, os encontros entre Chefes de Estado, a figura do Alto-

71 GROUX, J.; MANIN, P. Les communautés européennes dans l'ordre international. Luxembourg: OPOCE, 1984. p. 14.

72 GROUX, J.; MANIN, P. Les communautés européennes dans l'ordre international. Luxembourg: OPOCE, 1984. p. 14.

73 BENLOLO-CARABOT, Myriam; CANDAS, Ulas; CUJO, Eglantine. Union européenne et droit international. Paris: Pedone, 2012. p. 01. 
-Representante da União para os Negócios Estrangeiros e a Política de Segurança, maioria simples e absoluta, integração regional, a paz, os conflitos interestatais, não ocorre de maneira diversa com as outras 02 (duas) dimensões.

Outrossim, a dimensão jurídica molda sua forma em códigos e linguagens próprios como, por exemplo, diretrizes, estratégias comuns, posições comuns, acordos internacionais, efeitos vinculantes. Por último, a dimensão epistemológica permite apreender das 02 (duas) dimensões anteriores, num primeiro momento - de forma autônoma - e, numa segunda etapa — de forma interdependente - as características e os elementos que permitem decifrar o funcionamento, isto é, a forma, o modelo teórico de como cada dimensão se autorregula, gerando estabilidade e expectativas sociais. A partir desse primeiro passo, é possível chegar a uma análise crítica das dimensões, com vistas ao seu desenvolvimento enquanto sistemas sociais. Por exemplo, toda a evolução da Política Externa e de Segurança Comum (PESC) demonstrada pela consecução de diversas reuniões, formalização de Tratados de integração regional e desenvolvimento de mecanismos de execução dos consensos estatais e, posteriormente, regionais.

Entretanto, como esse debate contribui para a relação a ser estabelecida nesse item, sobre as relações paradoxais entre a Política Externa e de Segurança Comum (PESC) da União Europeia e o Direito das Nações Unidas? Em linhas gerais, tanto a teoria geral do Direito Internacional Público como a do chamado Direito da União consagram aspectos importantes de autonomia epistemológica. Entretanto, tal autonomia absoluta numa relação de dominação epistemológica entre os dois sistemas jurídicos - tem gerado uma ausência de diálogo e de reflexão sobre as relações entre estes dois sistemas jurídicos, tanto pelo que se pode chamar de doutrina europeanista — modelo que vê a União Europeia no seio da teoria geral das Organizações Internacionais — como da doutrina internacionalista. ${ }^{74}$

Essa problemática, surgida a partir da constatação do isolamento e pela ausência de diálogo entre as doutrinas europeanista e internacionalista, estabelece justamente, notadamente após a vigência do Tratado de Lisboa, como será observado a seguir, a relação paradoxal entre o

74 BENLOLO-CARABOT, Myriam; CANDAS, Ulas; CUJO, Eglantine. Union européenne et droit international. Paris: Pedone, 2012. p. 01.
Direito das Nações Unidas e o Direito da União. Em especial, em relação à autonomia normativa aparente entre o Direito da União e o Direito das Nações Unidas, bem como no que concerne à obrigatoriedade ou não de cumprimento das Resoluções do Conselho de Segurança das Nações Unidas (CSNU) pela União Europeia, em matéria de Política Externa e de Segurança Comum (PESC).

Nessa concepção geral, portanto, a preocupação geral será a de não perder a ideia de sistema, ${ }^{75}$ seja do sistema jurídico da União Europeia ou do sistema jurídico internacional, bem como a ideia de sistema social, a fim de não desnaturar a ideia de quadro jurídico-institucional de estabilidade, de integridade e de coerência normativas. Eis as questões jurídicas a serem trabalhadas a seguir.

\subsection{Da aparente autonomia à vinculação normativa da União Europeia ao Direito das Nações Unidas}

Uma das questões mais controvertidas até a entrada em vigor das modificações realizadas pelo Tratado de Lisboa, em 1 de dezembro de 2009, era a da aquisição ou não da personalidade jurídica internacional pela União Europeia ${ }^{76}$. Resolve, o Tratado de Lisboa, um dos aspectos mais controversos do Direito institucional da União Europeia, justamente, sobre a sua qualidade de sujeito de Direito Internacional.

Essa problemática histórico-institucional da construção de uma personalidade jurídica internacional para a União Europeia é essencial para se verificar o estabelecimento de uma vinculação normativa entre o Direito da União e o Direito das Nações Unidas, como será analisado a seguir. O reconhecimento da personalidade jurídica internacional, nesse sentido, retoma um elemento de aptidão do ente reconhecido para ser titular de direitos e, ao mesmo tempo, vinculado a obrigações instituídas normativamente. ${ }^{77}$

Independentemente das interessantes teses sobre o status de reconhecimento da União Europeia como Organização Internacional sui generis ${ }^{78}$ — posição adotada

75 Influência da concepção sistêmica de Niklas Luhmann. LUHMANN, Niklas. L a sociedad de la sociedade. Ciudad de México: Herder, $2006 .$. 76 Reconhecendo os estágios e as etapas de integração, obviamente, anteriores às modificações realizadas pelo Tratado de Lisboa. 77 DAILLIER, Patrick; FORTEAU, Mathias; PELLET, Alain. Droit international public. 8. ed. Paris: Lextenso, 2009.

78 BEULAY, Marjorie. Les traités constitutifs de l'Union Européenne. In: BENLOLO-CARABOT, Myriam; CANDAS, Ulas; 
no presente estudo - ou como Federação de Estados, ${ }^{79}$ a questão a ser tratada reside em saber se, mesmo sem se caracterizar tal status, há como se vincular o Direito da União ao Direito das Nações Unidas.

Levando-se em consideração a posição da União Europeia como uma Organização Internacional sui generis, observa-se que, na maioria dos casos, as Organizações Internacionais tem o reconhecimento de sua personalidade jurídica raramente realizado de forma explícita em seus atos constitutivos. Jurisprudencialmente, a Corte Internacional de Justiça (CIJ), no Parecer consultivo de 11 de abril de 1949 (CIJ, 2014), foi provocada a determinar se a Organização das Nações Unidas (ONU) tinha capacidade jurídica para apresentar uma reclamação internacional, deduzindo a personalidade jurídica de suas missões.

Esse silêncio dos atos constitutivos não autoriza por em dúvida a existência de personalidade jurídica internacional das Organizações Internacionais, tendo em vista "Que les actes de création soient silencieux sur ce point n'autorise pas à mettre en doute la possession d'une personalité juridique internationale." 80

$\mathrm{Na}$ União Europeia, inserida no silêncio do Tratado de Maastrich ao projeto de tratado constitucional, nenhum dispositivo de Direito primário foi inscrito no sentido de reconhecimento explícito da personalidade jurídica internacional da União. Tal aquisição, como se observará, dar-se-á somente após as modificações realizadas pelo Tratado de Lisboa.

Nesse mesmo intervalo, coexistiam as Comunidades Europeias, já tendo suas personalidades jurídicas reconhecidas ${ }^{81}$. Sendo assim, como se deu esse processo de reconhecimento normativamente e jurisprudencialmente das Comunidades Europeias?

Embora o artigo 245 do Tratado de Roma dispusesse que a Comunidade Europeia possuía personalidade jurídica - de forma genérica —, não o fez outrora da mesma maneira específica que o Tratado da Comunida-

CUJO, Eglantine. Union européenne et droit international. Paris: Éditions Pedone, 2012. p. 95-109.

79 SIMON, Denys. Invocabilité et primauté: petite éxperience de déconstruction. In: BENLOLO-CARABOT, Myriam; CANDAS, Ulas; CUJO, Eglantine. Union européenne et droit international. Paris: Pedone, 2012. p. 140-157.

80 DAILLIER, Patrick; FORTEAU, Mathias; PELLET, Alain. Droit international public. 8. ed. Paris: Lextenso, 2009. p. 658.

81 EDOUARD, Régis. La personnalité juridique internationale de l'Union Européenne. In: BENLOLO-CARABOT, Myriam; CANDAS, Ulas; CUJO, Eglantine. Union européenne et droit international. Paris, 2012. p. 110. de Econômica do Carvão e do Aço (CECA), em seu artigo $6^{\circ}$, 2: "A CECA tem capacidade jurídica nas suas relações internacionais." De forma mais paradoxal ainda, pois o próprio Tratado de Roma em seu artigo 282 reconhecia que a União Europeia gozava da mais ampla capacidade jurídica reconhecida às pessoas coletivas pelas legislações nacionais, isto é, a personalidade jurídica nas ordens jurídicas dos respectivos Estados membros. ${ }^{82}$

Mesmo com todas essas observações, normativamente, não era possível reconhecer, sem ambiguidades, pelo texto do Tratado de Roma, personalidade jurídica internacional à Comunidade Europeia, embora fossem reconhecidas competências externas como, por exemplo, a celebração de acordos internacionais com Estados ou Organizações Internacionais, conforme o artigo 300 do Tratado de Roma.

É justamente no Caso $A$ ETR $^{83}$, na decisão proferida em 31 de março de 1971, que se pode obter, com segurança, o reconhecimento da personalidade jurídica internacional da Comunidade Europeia. ${ }^{84} \mathrm{Na}$ interpretação do então artigo 210 do Tratado de Roma, a Corte de Justiça das Comunidades Europeias (CJCE) ${ }^{85}$ nos itens 13 e 14, constrói a tese da personalidade jurídica internacional, no seguinte sentido:

13. O artigo $210^{\circ}$ dispõe que «a Comunidade tem personalidade jurídica». 14. Esta disposição, colocada no cabeçalho da sexta parte do Tratado consagrada às «disposições gerais e finais», significa que, nas relações externas, a Comunidade goza da capacidade de estabelecer vínculos contratuais com Estados terceiros em toda a extensão do campo dos objectivos definidos na primeira parte do Tratado, da qual a sexta constitui o prolongamento. ${ }^{86}$

82 EDOUARD, Régis. La personnalité juridique internationale de l'Union Européenne. In: BENLOLO-CARABOT, Myriam; CANDAS, Ulas; CUJO, Eglantine. Union européenne et droit international. Paris: Pedone, 2012. p. 109-116. p. 111.

83 CORTE DE JUSTIÇA DAS COMUNIDADES EUROPEIAS. 1971. Sentença de 31 de março. Comissão das Comunidades Europeias contra Conselho das Comunidades Europeias. Processo n. 22/70. Disponível em: <http://curia.europa.eu/juris/showPdf.jsf?text $=\&$ docid $=88062 \&$ pageIndex $=0 \&$ doclang $=p t \&$ mode $=1$ st $\&$ dir $=\& o c c=$ first\&part=1\&cid=563437> . Acesso em: 2 fev. 2014.

84 EDOUARD, Régis. La personnalité juridique internationale de l'Union Européenne. In: BENLOLO-CARABOT, Myriam; CANDAS, Ulas; CUJO, Eglantine. Union européenne et droit international. Paris: Éditions Pedone, 2012. p. 112.

85 Após a entrada em vigor do Tratado de Lisboa, torna-se Tribunal de Justiça da União Europeia (TJUE).

86 CJCE (CORTE DE JUSTIÇA DAS COMUNIDADES EUROPEIAS). CORTE DE JUSTIÇA DAS COMUNIDADES EU- 
A novidade trazida pelo acórdão mencionado diz respeito ao reconhecimento da existência de competências externas implícitas, afirmando, no ponto 15, que: "Para fixar, num caso determinado, a competência da Comunidade para concluir acordos internacionais, há que tomar em consideração a sistematização do Tratado, e bem assim as suas disposições materiais." ${ }^{87}$ Além disso, no ponto 16, a Corte reconhece que tal competência não decorre somente de uma atribuição explícita feita pelo Tratado, mas pode decorrer igualmente de outras disposições do Tratado e de outros atos adotados, no âmbito destas disposições, pelas instituições da Comunidade. ${ }^{88}$ Sendo assim, a Comunidade Europeia aparecia como uma verdadeira organização internacional sui generis, titular de personalidade jurídica internacional, com certa capacidade jurídica para a produção de atos da vida internacional. ${ }^{89}$

Após o Tratado de Maastrich ou Tratado sobre a União Europeia (TUE), que cria a União Europeia, entrando em vigor em 1 de novembro de 1993, volta-se ao imbróglio acerca do reconhecimento da personalidade jurídica internacional. A problemática residia em que nenhum dispositivo do Tratado atribuía personalidade jurídica à União Europeia, mesmo nas ordens jurídicas dos Estados membros, como outrora ocorrera com o Tratado de Roma e de Paris. ${ }^{90}$

Além disso, outro argumento normativo que dificultava o reconhecimento da personalidade jurídica

ROPEIAS. 1971. Sentença de 31 de março. Comissão das Comunidades Europeias contra Conselho das Comunidades Europeias. Processo n. 22/70. Disponível em: <http://curia.europa.eu/juris/ showPdf.jsf text $=\&$ docid $=88062 \&$ pageIndex $=0 \&$ doclang $=$ pt $\&$ mode $=1$ st $\&$ dir $=\& o c c=$ first $\&$ part $=1 \&$ cid $=563437>$. Acesso em: 2 fev. 2014

87 CORTE DE JUSTIÇA DAS COMUNIDADES EUROPEIAS. 1971. Sentença de 31 de março. Comissão das Comunidades Europeias contra Conselho das Comunidades Europeias. Processo n. 22/70. Disponível em: < http://curia.europa.eu/juris/showPdf.js $\mathrm{f}$ ?text $=\&$ docid $=88062 \&$ pageIndex $=0 \&$ doclang $=$ pt\&mode $=$ lst $\&$ di $\mathrm{r}=\&$ occ $=$ first\&part $=1 \& \mathrm{cid}=563437>$. Acesso em: 2 fev. 2014 .

88 CORTE DE JUSTIÇA DAS COMUNIDADES EUROPEIAS. 1971. Sentença de 31 de março. Comissão das Comunidades Europeias contra Conselho das Comunidades Europeias. Processo n. 22/70. Disponível em: <http://curia.europa.eu/juris/showPdf.js f text $=\&$ docid $=88062 \&$ pageIndex $=0 \&$ doclang $=$ pt\&mode $=$ lst $\&$ di $\mathrm{r}=\&$ occ $=$ first\&part $=1 \& \mathrm{cid}=563437>$. Acesso em: 2 fev. 2014.

89 EDOUARD, Régis. La personnalité juridique internationale de l'Union Européenne. In: BENLOLO-CARABOT, Myriam; CANDAS, Ulas; CUJO, Eglantine. Union européenne et droit international. Paris: Pedone, 2012. p. 109-116. p. 112.

90 CHARPENTIER, J. De la personnalité juridique de l'Union européenne. In: GALABERT, J. M.; TERCINET, M.-R. Mélanges Peiser. Grenoble: Presses Universitaires de Grenoble, 1995. p. $93-$ 102. p. 95. internacional da União Europeia consistia na interpretação dos artigos $24^{91}$ e $38^{92}$ do Tratado de Maastricht concernentes à conclusão de acordos internacionais no sentido de que a capacidade de celebração pertencia aos Estados membros por intermédio do Conselho e não, efetivamente, à União Europeia. ${ }^{93}$

Em síntese, 02 (duas) linhas argumentativas em torno de obstáculos e 02 (duas) favoráveis, respectivamente, ao reconhecimento da personalidade jurídica internacional da União Europeia: ${ }^{94}$

a) a estrutura dos 03 (três) pilares dificultava a compreensão de uma personalidade jurídica internacional, distinta daquela das Comunidades Europeias, pois somente um verdadeiro sujeito de Direito Internacional deveria ter competência para tal;

b) negação da personalidade jurídica internacional por razões normativas em torno do Tratado sobre a União Europeia (TUE);

c) o artigo $2^{\circ}$ do Tratado sobre a União Europeia (TUE), na versão consolidada pelo Tratado de Amsterdam, que dispõe sobre a afirmação da identidade da União Europeia na cena internacional, nomeadamente por meio da execução de uma Política Externa e de Segurança Comum (PESC), que inclua a definição gradual de uma política de defesa comum;

d) existência de um quadro institucional próprio da União Europeia, em acordo ao Preâmbulo e ao artigo $3^{\circ}$ do Tratado sobre a União Europeia (TUE) ${ }^{95}$, na versão

91 Atual artigo 37 do Tratado sobre a União Europeia (TUE): “A União pode celebrar acordos com um ou mais Estados ou organizações internacionais nos domínios que se insiram no âmbito do presente capítulo.". UNIÃO EUROPEIA. Tratado sobre a União Europeia. Tratado de Maastricht. Disponível: <http://eur-lex.europa. $\mathrm{eu} / \mathrm{fr} /$ treaties/dat/11992M/htm/11992M.html >. Acesso em: 1 fev. 2014.

92 Revogado pelo Tratado sobre a União Europeia (TUE).

93 EDOUARD, Régis. La personnalité juridique internationale de l'Union Européenne. In: BENLOLO-CARABOT, Myriam; CANDAS, Ulas; CUJO, Eglantine. Union européenne et droit international. Paris: Éditions Pedone, 2012. p. 113.

94 EDOUARD, Régis. La personnalité juridique internationale de l'Union Européenne. In: BENLOLO-CARABOT, Myriam; CANDAS, Ulas; CUJO, Eglantine. Union européenne et droit international. Paris: Pedone, 2012. p. 109-116. p. 114.

95 "Artigo $3^{\circ}$. A União dispõe de um quadro institucional único, que assegura a coerência e a continuidade das acções empreendidas para atingir os seus objectivos, respeitando e desenvolvendo simultaneamente o acervo comunitário. A União assegurará, em especial, a coerência do conjunto da sua acção externa no âmbito das políticas que adoptar em matéria de relações externas, de segurança, de economia e de desenvolvimento. Cabe ao Conselho e à Comissão 
consolidada pelo Tratado de Amsterdam.

Por fim, cabe salientar que os 02 (dois) argumentos favoráveis, elaborados a partir da reflexão em torno das modificações realizadas pelo Tratado de Amsterdam no Tratado sobre a União Europeia (TUE), assinado em 2 de outubro de 1997, mas que entrou em vigor somente em 1 de maio de 1999, não prosperaram em razão da falta de vontade reiterada dos Estados em reconhecê-los, bem como não tiveram tempo de prosperar até a entrada em vigor das modificações trazidas pelo Tratado de Lisboa. ${ }^{96}$

Após a entrada em vigor das modificações realizadas pelo Tratado de Lisboa, em 13 de dezembro de 2007, toda a discussão sobre o reconhecimento da personalidade jurídica internacional da União Europeia torna-se desnecessária. Isso em razão de que vários dispositivos do Tratado sobre a União Europeia (TUE), modificado pelo Tratado de Lisboa, dispõem nesse sentido, em especial, o artigo 47: "A União tem personalidade jurídica." ${ }^{97}$

Obviamente, em virtude do artigo $5^{\circ}$ do Tratado sobre a União Europeia (TUE), a União Europeia submete-se à competência estrita delegada pelos Estados, pois "en effet, les Étas ont tenu à rappeler le caractère fonctionnel de cette personalité en specifiant que la détentrice de cette dernière ne pouvait pas agir au-délà des compétences qui lui sont attribués en vertu des traités." 98 As competências que não sejam atribuídas à União Europeia nos Tratados pertencem aos Estados membros, conforme o artigo $4^{\circ}$ do Tratado sobre a União Europeia (TUE).

a responsabilidade de assegurar essa coerência, cooperando para o efeito. O Conselho e a Comissão assegurarão a execução dessas políticas de acordo com as respectivas competências.”. UNIÃO EUROPEIA. Sinteses da legislação da União Europeia: Tratado de Amsterdam. Disponível em: <http://europa.eu/legislation_summaries/ institutional_affairs/treaties/amsterdam_treaty/a19000_pt.htm>. Acesso em: 31 jan. 2014.

96 EDOUARD, Régis. La personnalité juridique internationale de l'Union Européenne. In: BENLOLO-CARABOT, Myriam; CANDAS, Ulas; CUJO, Eglantine. Union européenne et droit international. Paris: Pedone, 2012. p. 109-116. p. 114.

97 UNIÃO EUROPEIA. Sinteses da legislação da União Europeia: Tratado de Amsterdam. Disponível em: <http://europa.eu/legislation_summaries/institutional_affairs/treaties/amsterdam_treaty/ a19000_pt.htm>. Acesso em: 31 jan. 2014.

98 EDOUARD, Régis. La personnalité juridique internationale de l'Union Européenne. In: BENLOLO-CARABOT, Myriam; CANDAS, Ulas; CUJO, Eglantine. Union européenne et droit international. Paris: Pedone, 2012. p. 109-116 . p. 115.
Além dos dispositivos mencionados, outra questão a ser observada reside no artigo $1^{\circ}$ do Tratado sobre a União Europeia (TUE), qual seja, a União substitui-se e sucede à Comunidade Europeia. Através dessa sucessão, pode inferir-se, logicamente, que o artigo $335^{99}$ do Tratado sobre o Funcionamento da União Europeia (TFUE) se aplica também à União, isto é, "Em cada um dos Estados-Membros a União goza da mais ampla capacidade jurídica reconhecida às pessoas colectivas pelas legislações nacionais [...]". ${ }^{100}$

Outro importante dispositivo do Tratado de Funcionamento sobre a União Europeia (TFUE) aplicável à União é o artigo 216, cuja transcrição segue:

\section{A União pode celebrar acordos com um ou mais países terceiros ou organizações internacionais quando os Tratados o prevejam ou quando a celebração de um acordo seja necessária para alcançar, no âmbito das políticas da União, um dos objectivos estabelecidos pelos Tratados ou quando tal celebração esteja prevista num acto juridicamente vinculativo da União, ou seja, susceptível de afectar normas comuns ou alterar o seu alcance. 2. Os acordos celebrados pela União vinculam as instituições da União e os Estados-Membros. ${ }^{101}$}

Consagrada a personalidade jurídica internacional da União, com as modificações realizadas pelo Tratado de Lisboa no Tratado sobre a União Europeia (TUE), com a prática de atos da vida internacional, conforme descrito nos dispositivos e nas teses anteriormente demonstradas, resta a seguinte questão: Em que base normativa se daria a vinculação da União Europeia ao Direito das Nações Unidas? Saliente-se que esse questionamento ainda não diz respeito à questão do cumprimento das decisões do Conselho de Segurança das Nações Unidas (CSNU) pela União, mas tão somente em relação à vinculação normativa entre ambas as instituições.

A vinculação normativa entre a União Europeia e o Direito das Nações Unidas deve ser tida numa concepção unitária do Direito, sem se perder a ideia do sistema jurídico como um todo, conforme demonstrado na própria Introdução e no item II do presente estudo. Assim,

99 Ex-artigo 282 do Tratado de Roma.

100 UNIÃO EUROPEIA. Tratado sobre a União Europeia: Consolidado com a versão do Tratado de Lisboa. Disponível: <http:// eur-lex.europa.eu/LexUriServ/LexUriServ.do?uri=OJ:C:2010:083: FULL:PT:PDF>. Acesso em: 1 fev. 2014.

101 UNIÃO EUROPEIA. Tratado sobre o Funcionamento da União Europeia. Disponível em: <http://eurlex.europa.eu/LexUriServ/ LexUriServ.do?uri=OJ:C:2010:083:0047:0200:pt:PDF>. Acesso em: 3 fev. 2014. 
não somente o Direito da União deve ser considerado na análise normativa da vinculação, mas também do Direito das Nações Unidas, ainda que de forma perfunctória para esse espaço.

De sorte que o Tratado sobre a União Europeia
(TUE) e o Tratado sobre o Funcionamento da União Europeia (TFUE) contém em diversos dispositivos que propiciam a defesa desta tese. Analisar-se-á o conjunto de dispositivos relativos ao Tratado sobre a União Europeia (TUE) e do Tratado de Funcionamento sobre a União Europeia (TFUE), no quadro abaixo exposto:

\begin{tabular}{|l|l|}
\hline Dispositivo & Implicação normativa \\
\hline $\begin{array}{l}\text { Artigo } \mathbf{3}^{\mathbf{0}}, \mathbf{5} \\
\text { (TUE) }\end{array}$ & $\begin{array}{l}\text { A União deve observância ao desenvolvimento do Direito Internacional, incluindo a Carta } \\
\text { das Nações Unidas. }\end{array}$ \\
\hline $\begin{array}{l}\text { Artigo 21, 1 } \\
\text { (TUE) }\end{array}$ & $\begin{array}{l}\text { A ação da União na cena internacional deve respeitar os princípios da Carta das Nações Uni- } \\
\text { das e do Direito Internacional. }\end{array}$ \\
\hline $\begin{array}{l}\text { Artigo 21, 2, c } \\
\text { (TUE) }\end{array}$ & $\begin{array}{l}\text { A União define políticas comuns e ações no sentido de assegurar um elevado grau de coo- } \\
\text { peração em todos os domínios das relações internacionais a fim de preservar a paz, preve- } \\
\text { nir conflitos e reforçar a segurança internacional, em conformidade com os objetivos e os } \\
\text { princípios da Carta das Nações Unidas. }\end{array}$ \\
\hline $\begin{array}{l}\text { Artigo 34,2 } \\
\text { (TUE) }\end{array}$ & $\begin{array}{l}\text { Os Estados-Membros da União, os membros do Conselho de Segurança das Nações Unidas, } \\
\text { defenderão, no exercício das suas funções, as posições e os interesses da União, sem prejuízo } \\
\text { das responsabilidades que lhes incumbem por força da Carta das Nações Unidas. }\end{array}$ \\
\hline $\begin{array}{l}\text { Artigo 42,1 } \\
\text { (TUE) }\end{array}$ & $\begin{array}{l}\text { A política comum de segurança e defesa faz parte integrante da política externa e de segu- } \\
\text { rança comum, devendo seguir os princípios da Carta das Nações Unidas. }\end{array}$ \\
\hline $\begin{array}{l}\text { Artigo 208, 2 } \\
\text { (TFUE) }\end{array}$ & $\begin{array}{l}\text { A União e os Estados-Membros respeitarão os compromissos e terão em conta os objetivos } \\
\text { aprovados no âmbito das Nações Unidas. }\end{array}$ \\
\hline
\end{tabular}

A análise dos artigos mencionados, que vinculam as ações, políticas e objetivos da União Europeia no respeito ao Direito Internacional e aos objetivos (artigo $1^{\circ}$ ) e princípios (artigo $2^{\circ}$ ) da Carta das Nações Unidas. Como a União Europeia está vinculada normativamente aos objetivos e princípios da Carta das Nações Unidas, está vinculada ao respeito à paz e à segurança internacionais. Consectário lógico disso é que as Resoluções expedidas pelo Conselho de Segurança das Nações Unidas em virtude do Capítulo VII da Carta - Ação em caso de ameaça à paz, ruptura da paz e ato de agressão são vinculantes à ação externa da União Europeia nesta matéria em que os Estados cedem competência.

Em decorrência disso, outro problema que emerge, pragmaticamente falando, diz respeito à incidência do artigo 103 da Carta das Nações Unidas, no caso de conflito entre as obrigações decorrentes do Capítulo VII da Carta - Ação em caso de ameaça à paz, ruptura da paz e ato de agressão — e as obrigações decorrentes da Política Externa e de Segurança Comum (PESC), da União. Quando houver suporte fático coincidente ou englobante entre estas ações que envolvem, ao mesmo tempo, questões de segurança e defesa — internacional e da União Europeia —, surge um conflito entre as obrigações decorrentes destas duas ordens jurídicas. Qual seria a possível resolução a essa relação paradoxal? Eis a problemática a ser tratada no próximo item desse estudo.

\subsection{A obrigatoriedade de cumprimento das Resoluções do Conselho de Segurança das Nações Unidas pela União Europeia em matéria de política externa e de segurança comum}

Le respect des engagements pris dans le cadre des Nations Unies s'impose tout autant dans le domaine du maintien de la paix et de la sécurité internationales, lors de la mise en oeuvre par la Communauté, par l'adoption d'actes communautaires pris sur le fondement des articles 60 CE [75 TFUE] et 301 CE [215 TFUE], de résolutions adoptées par le Conseil de Sécurité au titre du chapitre VII de la charte des Nations Unies. ${ }^{102}$

102 CORTE DE JUSTIÇA DAS COMUNIDADES EUROPEIAS. 2005. Sentença de 21 de setembro. Kadi contra Conselho das Comunidades Europeias. Processo n.T-315/01. Disponível em: $<$ http:/ / curia.europa.eu/juris/showPdf.jsf;jsessionid=9ea7d2dc30 dba52e7a050ed6467490eb8a6d82ddd35e.e34KaxiLc3qMb40Rch0 SaxuKbNb0?text $=\&$ docid $=65739$ \&pageIndex $=0 \&$ doclang $=$ PT $\&$ mode $=$ req $\&$ dir $=\& o c c=$ first $\&$ part $=1 \&$ cid $=220515>$. Acesso em: 2 fev. 2014 
Considerando a personalidade jurídica internacional e o vínculo da União Europeia com o Direito das Nações Unidas, conforme se desenvolveu nas teses anteriores, a questão que se coloca é a seguinte: Em uma concepção unitária, integrativa e estável do sistema jurídico ${ }^{103}$, em caso de conflito entre o conteúdo das obrigações decorrentes das Resoluções proferidas pelo Conselho de Segurança das Nações Unidas (CSNU), em função do Capítulo VII da Carta das Nações Unidas - Ação em caso de ameaça à paž, ruptura da paž e ato de agressão - e as obrigações decorrentes da Política Externa e de Segurança Comum (PESC), a União Europeia deve fazer prevalecer quais obrigações juridicamente? Existe uma resposta normativa a esse questionamento?

Segundo o artigo $3^{\circ}, 5$, do Tratado sobre a União Europeia (TUE), a União obrigou-se a respeitar os princípios da Carta das Nações Unidas e do Direito Internacional. Além disso, em virtude do artigo 42, 1, a União pode recorrer à capacidade operacional que lhe reconhecem os seus Estados membros nas missões fora da União a fim de assegurar a manutenção da paz, a prevenção dos conflitos e o reforço da segurança internacional. ${ }^{104}$

Além disso, pela Declaração no 13 sobre a Política Estrangeira e de Segurança Comum, anexada ao Tratado de 13 de dezembro de 2007, a Conferência de Lisboa reforça que a União Europeia e seus Estados membros permanecerão ligados às disposições da Carta das $\mathrm{Na}$ ções Unidas e, em particular, à responsabilidade principal, incumbindo ao Conselho de Segurança das Nações Unidas (CSNU) e a seus Estados membros a manutenção da paz e da segurança internacionais.

No plano jurisprudencial, no item 294 do acórdão proferido no caso Kadi I (CJCE, 2014b), a Corte de Justiça das Comunidades Europeias (CJCE) resume bem a problemática das relações entre a União e as obrigações decorrentes do Direito das Nações Unidas, em matéria de paz, segurança e defesa internacionais. Refere que no exercício da competência de adoção, por atos comunitários, das Resoluções tomadas pelo Conselho de Segu-

103 Por uma teoria sistêmica e social do Direito Internacional Público, ver: CRAWFORD, James. Chance, Order, Change: The Course of International Law. General Course on Public International Law. Leiden/ Boston: Martinus Nijhoff Publishers / Brill Academic, 2014 104 PELLET, Alain. Les sanctions de l'Union Européenne. In: BENLOLO-CARABOT, Myriam; CANDAS, Ulas; CUJO, Eglantine. Union européenne et droit international. Paris: Éditions Pedone, 2012. p. 433. rança das Nações Unidas (CSNU), a União Europeia deve dar atenção particular ao fato de que, conforme o artigo 24 da Carta das Nações Unidas, as Resoluções expedidas pelo Conselho de Segurança, em virtude do capítulo VII da Carta das Nações Unidas, constituem o exercício da responsabilidade principal desse órgão na manutenção da paz e da segurança internacionais. ${ }^{105}$

Além disso, reconhece ao Conselho de Segurança das Nações Unidas (CSNU), nessa advertência à União, o seu poder de determinar o que constitui uma ameaça contra a paz e a segurança internacionais, bem como tomar as medidas necessárias para mantê-las ou reestabelecê-las. ${ }^{106}$ Nesse ponto, reside, ao ver do presente estudo, uma questão central do diálogo entre o Direito das Nações Unidas e o Direito da União, em matéria de Política Externa e de Segurança Comum (PESC).

O problema da indeterminação conceitual no Direito das Nações Unidas, em especial no que tange ao conteúdo das Resoluções do Conselho de Segurança das Nações Unidas (CSNU), constitui uma importante ferramenta ao sistema de exclusão internacional exercido pela Organização das Nações Unidas (ONU) $\cdot{ }^{107}$ A gravidade desta concepção - caso se reconheça a prevalência da posição acerca das obrigações assumidas pela União Europeia em relação à Carta das Nações Unidas em detrimento do Direito da União — pode trazer uma série de imposições indiscriminadas do Conselho de Segurança das Nações Unidas (CSNU), por meio das Resoluções, à União Europeia em matéria de segurança e defesa europeias.

105 CORTE DE JUSTIÇA DAS COMUNIDADES EUROPEIAS. 2005. Sentença de 21 de setembro. Kadi contra Conselho das Comunidades Europeias. Processo n.T-315/01. Disponível em: $<$ http:/ / curia.europa.eu/juris/showPdf.jsf;jsessionid=9ea7d2dc30 dba52e7a050ed6467490eb8a6d82ddd35e.e34KaxiLc3qMb40Rch0 SaxuKbNb0?text $=\&$ docid $=65739$ \&pageIndex $=0 \&$ doclang $=P T \&$ mode $=$ req $\&$ dir $=\& o c c=$ first $\&$ part $=1 \&$ cid $=220515>$. Acesso em: 2 fev. 2014..

106 CORTE DE JUSTIÇA DAS COMUNIDADES EUROPEIAS. 2005. Sentença de 21 de setembro. Kadi contra Conselho das Comunidades Europeias. Processo n.T-315/01. Disponível em: $<$ http:// curia.europa.eu/juris/showPdf.jsf;jsessionid=9ea7d2dc30 dba52e7a050ed6467490eb8a6d82ddd35e.e34KaxiLc3qMb40Rch0 SaxuKbNb0?text $=\&$ docid $=65739$ \&pageIndex $=0 \&$ doclang $=$ PT $\&$ mode $=$ req $\&$ dir $=\& o c c=$ first $\&$ part $=1 \&$ cid $=220515>$. Acesso em: 2 fev. 2014..

107 Sobre a problemática do (des)controle das Resoluções do Conselho de Segurança das Nações Unidas (CSNU), ver: CRAWFORD, James. Chance, order, change: the course of international law. general course on public international law. Leiden: M. Nijhoff, 2014 .. p. 281-305. Ver também: CORTEN, Olivier. Le discours du droit international: pour un positivisme critique. Paris: Éditions Pedone, 2009. 
Explica-se esse fenômeno em razão de que para se obter maior liberdade e extensão em suas ações, instrumentalizadas sobretudo pelo Conselho de Segurança das Nações Unidas (CSNU), uma margem internacional de apreciação outorga, na extensão conceitual das categorias jurídicas — de maneira despótica —, uma aparência de maior legitimidade quando da tomada de decisões no concerto das controvérsias em matéria de paz e segurança mundiais, como, por exemplo:

Il y a dix ans, une période sembable a été l'occasion pour que se manifestent également des tentatives hégémoniques sous prétexte d'une «notion plus étendue de sécurité ». Par une résolution décisive adoptée en 1991, le Conseil de sécurité qualifia les problèmes économiques, sociaux, humanitaires et même écologiques, de «menaces à la paix et à la sécurité internationales » (S/23500 du 31 janvier 1991). Ceci représentait une possibilité d'extension sans précédent de la compétence du Conseil de sécurité - un coup d'état concernant des questions qui étaient auparavant traitées par l'Assemblée générale. ${ }^{108}$

Sendo assim, se as Resoluções proferidas pelo Conselho de Segurança das Nações Unidas (CSNU) — em virtude do capítulo VII da Carta —, mesmo que com um grau elevado de indeterminação das categorias da paz e de segurança - devem ser adotadas pela União Europeia, a possibilidade de intervenção do Direito das Nações Unidas dentro da ordem jurídica da União Europeia, na execução da Política Externa e de Segurança Comum (PESC), pode descaracterizar o modelo europeu constituído nos moldes delineados pela parte I deste estudo.

Contudo, foram analisados até o presente momento somente os efeitos das Resoluções do Conselho de Segurança das Nações Unidas (CSNU) na União Europeia, nos moldes supracitados, em caso de incidência direta e de adoção automática pela União. Agora, voltando-se ao questionamento proposto acerca do conflito entre o conteúdo das obrigações decorrentes das Resoluções proferidas pelo Conselho de Segurança das Nações Unidas (CSNU), em função do Capítulo VII da Carta das Nações Unidas - Ação em caso de ameaça à paz, ruptura da paz, e ato de agressão — e as obrigações decorrentes da Política Externa e de Segurança Comum (PESC) europeia, quais obrigações prevaleceriam?

108 KOSKENNIEMI, Martti. La politique du droit international. Paris: Pedone, 2007. p. 311.
Um apontamento inicial a ser realizado para responder esse questionamento é o de que todos os Estados membros da União Europeia fazem parte da Organização das Nações Unidas (ONU) ${ }^{109}$. Individualmente, todos os Estados-membros da União Europeia têm a obrigação de aplicar, por exemplo, as sanções ${ }^{110}$ impostas pelo Conselho de Segurança das Nações Unidas (CSNU) em respeito ao capítulo VII da Carta. ${ }^{111}$

Esta obrigação decorrente do capítulo VII da Carta das Nações Unidas, quando em conflito com uma obrigação relativa à Política Externa e de Segurança Comum (PESC), prevalece?

A resposta é afirmativa, tendo a União Europeia, nesse caso, o dever jurídico de cumprir a Resolução do Conselho de Segurança das Nações Unidas (CSNU), em decorrência do artigo 103 da Carta das Nações Unidas, que prescreve o seguinte: "No caso de conflito entre as obrigações dos membros das Nações Unidas em virtude da presente Carta e as obrigações resultantes de qualquer outro acordo internacional, prevalecerão as obrigações assumidas em virtude da presente Carta." ${ }^{112}$ Nessa leitura do artigo 103 da Carta das Nações Unidas, as obrigações resultantes de qualquer outro acordo internacional são justamente, no presente artigo, as assumidas pela União Europeia em decorrência de seu próprio Direito.

Convém salientar que inúmeras das obrigações mencionadas são de competência exclusiva da União Europeia, sendo lógico que para cumprir com suas obrigações em virtude da Carta das Nações Unidas, os Estados membros da União Europeia tem a obrigação de tomar todas as medidas necessárias para que a União Europeia execute, por exemplo, as sanções obrigatórias impostas pelo Conselho de Segurança. ${ }^{113}$

109 A Organização das Nações Unidas (ONU) conta, atualmente, com 193 Estados membros.

110 De acordo com o artigo 41 da Carta das Nações Unidas, tais medidas podem incluir a interrupção completa ou parcial das relações econômicas, dos meios de comunicação ferroviários, marítimos, aéreos, postais, telegráficos, radiofônicos, ou de qualquer outra espécie e o rompimento das relações diplomáticas.

111 PELLET, Alain. Les sanctions de l'Union Européenne. In: BENLOLO-CARABOT, Myriam; CANDAS, Ulas; CUJO, Eglantine. Union européenne et droit international. Paris: Pedone, 2012. p. 431-455. p. 435.

112 NATIONS UNIES. Charte des nations unies. Disponível em: $<$ http://www.un.org/fr/documents/charter/index.shtml >. Acesso em: 02 fev. 2014.

113 PELLET, Alain. Les sanctions de l'Union Européenne. In: BENLOLO-CARABOT, Myriam; CANDAS, Ulas; CUJO, Eglantine. Union européenne et droit international. Paris: Pedone, 2012. p. 431- 
O artigo 103 da Carta das Nações Unidas “[...] est une règle secondaire, qui se greffe sur des dispositions de fond de la Charte. Elle contient une règle de conflit d'obligations et non pas de normes." 114 Como regra de conflito de obrigações, o artigo 103 da Carta das Nações Unidas estabelece uma primazia das obrigações decorrentes da Carta das Nações Unidas em relação às obrigações decorrentes do Direito da União, justamente quando houver conflito entre as obrigações decorrentes do Capítulo VII da Carta - Ação em caso de ameaça à paz, ruptura da paz e ato de agressão - e as obrigações decorrentes da Política Externa e de Segurança Comum (PESC), da União Europeia. Assim, na existência de colisão entre suportes fáticos das ações que envolvam, ao mesmo tempo, questões de segurança e defesa - internacional e da União Europeia (PESC) -, o conflito obrigacional originado nestas duas ordens jurídicas deve ser solucionado pela primazia das obrigações decorrentes do Direito das Nações Unidas.

\section{Considerações finais}

O presente artigo teve por objetivo estabelecer as relações entre o Direito das Nações Unidas e o Direito da União Europeia em matéria de Política Externa e de Segurança Comum (PESC), inseridas na sociedade internacional. Para tanto, conforme a própria perspectiva adotada propôs durante a exposição, a preocupação central era a de não se perder a ideia de sistema, seja do sistema jurídico, do sistema político, bem como do sistema social, com vistas a não descaracterização desses enquanto molduras de estabilidade, integridade e coerência internacionais. A compreensão do Direito Internacional Público como um sistema social, antes de tudo, demonstra a integridade, a estabilidade e a coerência desse conjunto normativo. ${ }^{115}$

A reconstrução histórico-institucional da União Europeia, em especial, da problemática da Política Externa

455. p. 435.

114 Para uma discussão completa sobre a natureza, função e completude do artigo 103 da Carta das Nações Unidas, ver o magistral Curso de Robert Kolb na Academia de Direito Internacional da Haia, em 2013. KOLB, Robert. L'article 103 de la Charte des Nations Unies. Leiden: M. Nijhoff, 2014.. p. 329.

115 CRAWFORD, James; KOSKENNIEMI, Martti. The Cambridge Companion to International Law. Cambridge: Cambridge University Press, 2012. p. 11; CRAWFORD, James; KOSKENNIEMI, Martti. The Cambridge Companion to International Law. Cambridge: Cambridge University Press, 2012. e de Segurança Comum (PESC), por meio do critério de diferenciação funcional ${ }^{116}$, permitiu ao observador (re)construir a autonomia das categorias jurídicas e, por conseguinte, dotá-las da riqueza semântica que as suporta, revelando a emergência do diálogo das categorias do Direito da União e do Direito das Nações Unidas.

Com vistas ao desenvolvimento do estudo proposto, elencou-se o seguinte problema de pesquisa, agora retomado para fins de conclusão: quando houver prescrições divergentes entre as obrigações decorrentes da Política Externa e de Segurança Comum Europeia (PESC) e de Paz e de Segurança Internacionais - em virtude das Resoluções expedidas pelo Conselho de Segurança com base no capítulo VII da Carta das Nações Unidas -, decorrentes, portanto, de obrigações assumidas em virtude do Direito da União e do Direito das Nações Unidas, haveria uma relação de primazia?

A resposta foi afirmativa, no sentido de que há uma relação de primazia obrigacional entre o Direito das $\mathrm{Na}$ ções Unidas e o Direito da União, sendo que na existência de colisão entre suportes fáticos das ações que envolvam, ao mesmo tempo, questões de segurança e defesa - internacional e da União Europeia (PESC) -, o conflito obrigacional originado entre essas duas ordens jurídicas deve ser solucionado pela primazia das obrigações decorrentes do Direito das Nações Unidas. Assim, instaurada, portanto, a primaz̧ia das obrigações do Direito das Nacõos Unidas.

Ao tentar fugir das clássicas discussões jurídicas acerca de uma postura europeanista ou internacionalista, por critérios de exclusão ou de dominação epistemológica de um sistema jurídico ao outro, portanto, o presente estudo teve por fim, claramente delimitado, a iluminação dos paradoxos inerentes ao diálogo entre o Direito da União e o Direito das Nações Unidas, num movimento pendular entre o que se poderia chamar de solipsismo onusiano e de solipsismo europen.

\section{REFERÊNCIAS}

BENLOLO-CARABOT, Myriam; CANDAS, Ulas; CUJO, Eglantine. Union européenne et droit international. Paris: Pedone, 2012.

116 LUHMANN, Niklas. La sociedad de la sociedade. Ciudad de México: Herder, 2006. 
BEULAY, Marjorie. Les traités constitutifs de l'Union Européenne. In: BENLOLO-CARABOT, Myriam; CANDAS, Ulas; CUJO, Eglantine. Union européenne et droit international. Paris: Pedone, 2012. p. 95-109.

BOISSON DE CHAZOURNES, Laurence. Les relations entre organisations régionales et organisations universelles. In: L'ACADÉMIE DE DROIT INTERNATIONAL DE LA HAYE. Recueil des cours de l'Académie du droit international de la Haye. Leiden: M. Nijhoff, 2011. t. 2. p. 79-406.

CENTRE VIRTUEL DE LA CONNAISANCE DE L'EUROPE. Rapport Copenhague: Deuxième rapport sur la coopération politique européenne en matière de politique étrangère. Disponível em: <http://www.cvce. eu/obj/deuxieme_rapport_sur_la_cooperation_politique_europeenne_en_matiere_de_politique_etrangere_ copenhague_23_juillet_1973-fr-8b935ae1-0a38-42d4a97e-088c63d54b6f.html>. Acesso em: 02 fev. 2014.

CENTRE VIRTUEL DE LA CONNAISANCE DE L'EUROPE. Rapport Davignon: rapport des ministres des affaires étrangères des Etats membres sur les problèmes de l'unification politique. Disponível em: $<$ http://www.cvce.eu/obj/rapport_davignon_luxembourg_27_octobre_1970-fr-4176efc3-c734-41e5-bb90d34c4d17bbb5.html>. Acesso em: 01 fev. 2014.

CENTRE VIRTUEL DE LA CONNAISANCE DE L'EUROPE. Rapport Londres: rapport sur la coopération politique européenne (Londres, 13 octobre 1981). Disponível em: <http://www.cvce.eu/obj/rapport_sur_la_cooperation_politique_europeenne_londres_13_octobre_1981-fr-869a63a6-4c28-4e42-8c41efd2415cd7dc.html>. Acesso em: 02 fev. 2014.

CENTRE VIRTUEL DE LA CONNAISANCE DE L'EUROPE. Sommet de Paris: Communiqué final de la réunion des chefs de gouvernement de la Communauté (Paris, 9 et 10 décembre 1974). Disponível em: <http:// www.cvce.eu/obj/communique_final_du_sommet_ de_paris_9_et_10_decembre_1974-fr-2acd8532-b27149ed-bf63-bd8131180d6b.html>. Acesso em: 02 fev. 2014.

CHARPENTIER, J. De la personnalité juridique de l'Union européenne. In: GALABERT, J. M.; TERCINET, M.-R. Mélanges Peiser. Grenoble: Presses Universitaires de Grenoble, 1995. p. 93-102.

CORTE DE JUSTIÇA DAS COMUNIDADES EUROPEIAS. 1971. Sentença de 31 de março. Comissão das Comunidades Europeias contra Conselho das Comunidades Europeias. Processo n. 22/70. Disponível em: <http://curia.europa.eu/juris/showPdf.jsf?text= $\&$ docid $=88062 \&$ pageIndex $=0 \&$ doclang $=$ pt $\&$ mode $=1 \mathrm{~s}$ $\mathrm{t} \& \operatorname{dir}=\&$ occ $=$ first\&part $=1 \& \mathrm{cid}=563437>$. Acesso em: 2 fev. 2014.

CORTE DE JUSTIÇA DAS COMUNIDADES EUROPEIAS. 2005. Sentença de 21 de setembro. Kadi contra Conselho das Comunidades Europeias. Processo n.T-315/01. Disponível em: <http://curia.europa. $\mathrm{eu} /$ juris $/$ showPdf.jsf;jsessionid=9ea $7 \mathrm{~d} 2 \mathrm{dc} 30 \mathrm{dba} 52 \mathrm{e} 7 \mathrm{a}$ 050ed6467490eb8a6d82ddd35e.e34KaxiLc3qMb40Rc h0SaxuKbNb0? text $=\&$ docid $=65739 \&$ pageIndex $=0 \&$ doclang $=$ PT $\&$ mode $=$ req $\&$ dir $=\&$ occ $=$ first $\&$ part $=1 \& \mathrm{c}$ id $=220515>$. Acesso em: 2 fev. 2014.

CORTEN, Olivier. Le discours du droit international: pour un positivisme critique. Paris: Pedone, 2009.

COUR INTERNATIONALE DE JUSTICE. Réparation des dommages subis an service des Nations Unies. Disponível em: <http://www.icj-cij.org/docket/index.ph $\mathrm{p}$ ? $1=3 \& \mathrm{p} 2=4 \& \mathrm{k}=41 \&$ case $=4 \& \operatorname{code}=$ isun $\& \mathrm{p} 3=0>$. Acesso em: 04 fev. 2014.

CRAWFORD, James. Chance, order, change: the course of international law. general course on public international law. Leiden: M. Nijhoff, 2014.

CRAWFORD, James; KOSKENNIEMI, Martti. The Cambridge Companion to International Law. Cambridge: Cambridge University Press, 2012.

DAILLIER, Patrick; FORTEAU, Mathias; PELLET, Alain. Droit international public. 8. ed. Paris: Lextenso, 2009.

EDOUARD, Régis. La personnalité juridique internationale de l'Union Européenne. In: BENLOLO-CARABOT, Myriam; CANDAS, Ulas; CUJO, Eglantine. Union européenne et droit international. Paris: Pedone, 2012. p. 109-116.

ESTAING, Valéry Giscard. Discours introductif à la Convention sur l'avenir de l'Europe. Disponível em: < http:/ / www.senat.fr/europe/convention_2002/discours_ vge_28022002.pdf>. Acesso em: 03 fev. 2014.

FRANCE. Ministère des Affaires Étrangères). Guide de la PESC. Disponível em: <http://www.rpfrance.eu/ IMG/guide_pesc.pdf>. Acesso em: 2 fev. 2014.

GROUX, J.; MANIN, P. Les communautés européennes dans l'ordre international. Luxembourg: OPOCE, 1984. 
IORDAN, Cristian. La définition progressive d'une politique européenne de sécurité. Romanian Journal Of European Affairs, Bucharest, v. 13, n. 2, p. 67-79, 2013.

KING, Anthony. The future of the european security and defence policy. Contemporary Security Policy, Virginia, v. 26, n. 1, p. 44-61, 2005.

KOLB, Robert. L'article 103 de la Charte des Nations Unies. Leiden: M. Nijhoff, 2014.

KOSKENNIEMI, Martti. From apology to utopia: the structure of the international legal argument. Cambridge: Cambridge University Press, 2005.

KOSKENNIEMI, Martti. La politique du droit international. Paris: Pedone, 2007.

LUHMANN, Niklas. La sociedad de la sociedade. Ciudad de México: Herder, 2006.

MARTINS, Estevão de Rezende. Parcerias almejadas: política externa, segurança, defesa e história na Europa. Belo Horizonte: Fino Traço, 2012.

NATIONS UNIES. Charte des nations unies. Disponível em: <http://www.un.org/fr/documents/charter/index.shtml>. Acesso em: 02 fev. 2014.

PELLET, Alain. Les sanctions de l'Union Européenne. In: BENLOLO-CARABOT, Myriam; CANDAS, Ulas; CUJO, Eglantine. Union européenne et droit international. Paris: Pedone, 2012. p. 431-455.

PETITEVILLE, Franck. La politique internationale de l'union européenne. Paris: Les Presses de Sciences Po, 2006.

RICHARDSON, John. Existencial epistemology: a heideggerian critique of the cartesian project. New York: Oxford University Press, 1986.

SCHUMAN, Robert. La déclaration Schuman du 9 mai 1950. Disponível em: <http://europa.eu/about-eu/ basic-information/symbols/europe-day/schuman-declaration/index_fr.htm>. Acesso em: 03 fev. 2014.

SIMON, Denys. Invocabilité et primauté: petite éxperience de déconstruction. In: BENLOLO-CARABOT, Myriam; CANDAS, Ulas; CUJO, Eglantine. Union européenne et droit international. Paris: Pedone, 2012. p. 140-157.

TERPAN, Fabien. La politique étrangère, de sécurité et de défense de l'union européenne. Paris: La Documentation Française, 2010.

TRINDADE, Antônio Augusto Cançado. Os tribunais internacionais contemporâneos. Brasília: FUNAG, 2013.
UNIÃO EUROPEIA. Carta dos Direitos Fundamentais da União Europeia. Disponível em: <http://www.europarl. europa.eu/charter/pdf/text_pt.pdf $>$. Acesso em: 3 fev. 2014.

UNIÃO EUROPEIA. Sinteses da legislação da União Europeia. Disponível em: <http://europa.eu/legislation_ summaries/institutional_affairs/treaties/treaties_introduction_pt.htm>. Acesso em: 30 jan. 2014.

UNIÃO EUROPEIA. Sinteses da legislação da União Europeia: Tratado de Amsterdam. Disponível em: <http:// europa.eu/legislation_summaries/institutional_affairs/ treaties/amsterdam_treaty/a19000_pt.htm>. Acesso em: 31 jan. 2014.

UNIÃO EUROPEIA. Sinteses da legislação da União Europeia: Ato Único Europeu (AUE). Disponível em: $<$ http://europa.eu/legislation_summaries/institutional_affairs/treaties/treaties_singleact_pt.htm>. Acesso em: 1 fev. 2014.

UNIÃO EUROPEIA. Tratado de Amsterdam. Disponível em: <http://eur-lex.europa.eu/fr/treaties/ dat/11997D/htm/11997D.html>. Acesso em: 1 fev. 2014.

UNIÃO EUROPEIA. Tratado sobre a União Europeia. Tratado de Maastricht. Disponível: <http://eur-lex.europa.eu/fr/treaties/dat/11992M/htm/11992M.html>. Acesso em: 1 fev. 2014.

UNIÃO EUROPEIA. Tratado sobre a União Europeia: Consolidado com a versão do Tratado de Lisboa. Disponível: <http://eur-lex.europa.eu/LexUriServ/ LexUriServ.do?uri=OJ:C:2010:083:FULL:PT:PDF>. Acesso em: 1 fev. 2014.

UNIÃO EUROPEIA. Tratado sobre o Funcionamento da União Europeia. Disponível em: <http://eurlex.europa. eu/LexUriServ/LexUriServ.do?uri=OJ:C:2010:083:004 7:0200:pt:PDF>. Acesso em: 3 fev. 2014.

VIGNES, Daniel. L'Union européenne, acteur civil et militaire dans la gestion des crises internationales: la PESD, politique européenne de sécurité et de défense. In: YEE, Sienho; MORIN, Jacques-Yvan. Multiculturalism and international law: essays in honour of Edward McWhinney. Leiden: Martinus Nijhoff, 2009. p. 393414.

VISSCHER, Charles de. Teorias y realidades en derecho internacional público. Barcelona: Bosch, 1962. 
Para publicar na Revista de Direito Internacional, acesse o endereço eletrônico www.rdi.uniceub.br ou www.brazilianjournal.org.

Observe as normas de publicação, para facilitar e agilizar o trabalho de edição. 